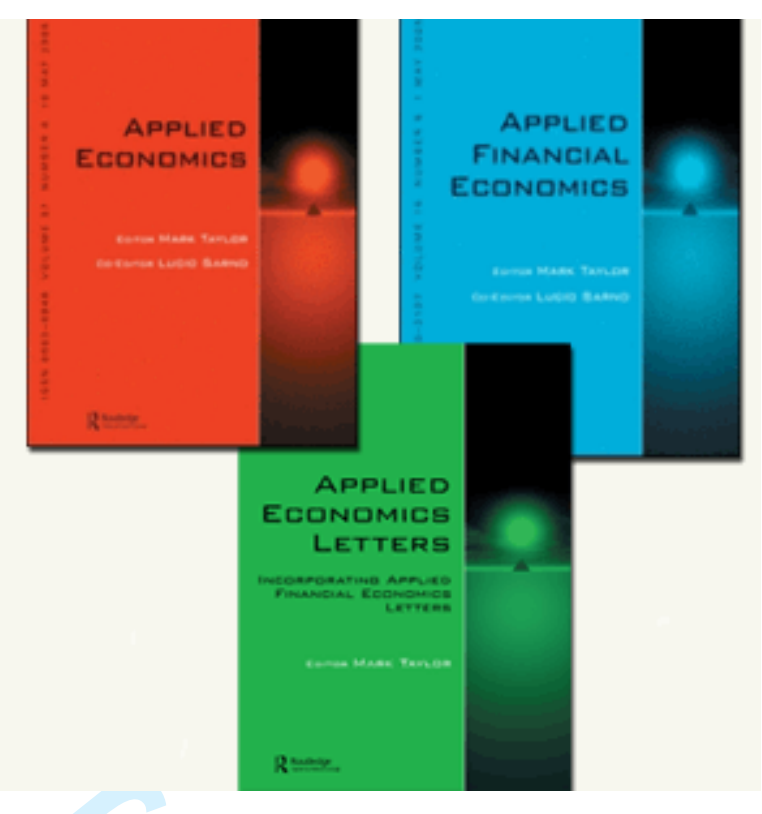

\title{
Arbitrage Costs and Nonlinear Adjustment in the G7 Stock Markets
}

\begin{tabular}{|c|c|}
\hline Journal: & Applied Economics \\
\hline Manuscript ID: & APE-2010-0284.R1 \\
\hline Journal Selection: & Applied Economics \\
\hline $\begin{array}{r}\text { Date Submitted by the } \\
\text { Author: }\end{array}$ & $10-N o v-2010$ \\
\hline Complete List of Authors: & $\begin{array}{l}\text { JAWADI, Fredj; University of Evry Val d'Essonne \& Amiens School of } \\
\text { Management } \\
\text { prat, Georges; Université Paris Ouest Nanterre La Défense, } \\
\text { EconomiX-CNRS }\end{array}$ \\
\hline JEL Code: & $\begin{array}{l}\text { C22 - Time-Series Models < C2 - Econometric Methods: Single } \\
\text { Equation Models < C - Mathematical and Quantitative Methods, G15 } \\
\text { - International Financial Markets < G1 - General Financial Markets } \\
\text { < G - Financial Economics }\end{array}$ \\
\hline Keywords: & Stock price, heterogeneous transaction costs, STECMs \\
\hline
\end{tabular}

\section{SCHOLARONE ${ }^{m}$ \\ Manuscripts}




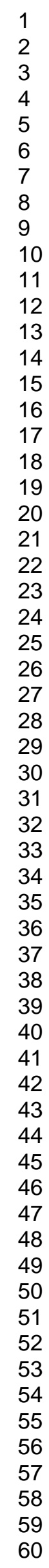

14

15

16

18

19

20

22

23

25

26

27

29

30

32

33

34

35

36

37

38

41

42

44

45

46

47

48

49

51

52

53

54

56

57

58

60

Editorial Office, Dept of Economics, Warwick University, Coventry CV4 7AL, UK 


\title{
Arbitrage Costs and Nonlinear Adjustment in the G7 Stock Markets
}

\author{
Fredj JAWADI ${ }^{+}$and Georges PRAT $\varnothing$
}

\begin{abstract}
This paper aims to study stock price adjustments toward fundamentals due to the existence of arbitrage costs defined as the sum of transaction costs and a risky arbitrage premium associated with the uncertainty characterizing the fundamentals. Accordingly, it is shown that a two-regime STECM (Smooth Transition Error Correction Model) is appropriate to reproduce the dynamics of stock price deviations from fundamentals in the G7 countries during the period 1969-2005. This model takes into account the interdependences or contagion effects between stock markets. Deviations appear to follow a quasi random walk in the central regime when prices are near fundamentals (i.e. when arbitrage costs are greater than expected arbitrage profits, the mean reversion mechanism is inactive), while they approach a white noise in the outer regimes (i.e. when arbitrage costs are lower than expected arbitrage profits, the mean reversion is active). Interestingly, as expected when arbitrage costs are heterogeneous, the estimated STECM shows that stock price adjustments are smooth and that the convergence speed depends on the size of the deviation. Finally, using two appropriate indicators proposed by Peel and Taylor (2000), both the magnitudes of under- and overvaluation of stock price and the adjustment speed are calculated per date in the G7 countries. These indicators show that the dynamics of stock price adjustment are strongly dependent on both the date and the country under consideration.
\end{abstract}

JEL: C22, G15.

Keywords: Stock price, heterogeneous transaction costs, STECMs.

\footnotetext{
${ }^{+}$Corresponding author: University of Evry (UFR Sciences de gestion et sciences sociales, 2, rue Facteur Cheval, 91000 Evry)) \& Amiens School of Management \& EconomiX-CNRS Tel: +33 (0) 3228224 41. E-mail: fredj.jawadi@univ-evry.fr.

ÐconomiX, CNRS and University of Paris Ouest Nanterre la Défense, Bât. G, 200 avenue de la République, 92001 Nanterre. Tel: + 33 (0) 1409759 68. E-mail: georges.prat@u-paris10.fr
} 


\section{Arbitrage Costs and Nonlinear Adjustment in the G7}

\section{Stock Markets}

\section{1- Introduction}

Many studies suggest that fundamentals alone cannot explain stock price dynamics since deviations between the market price and fundamentals are often large and durable (among others, see Shiller (1981), Campbell and Shiller (2001), Allen and Yang (2001), Manzan (2003), Boswijk et al. (2007)). Deviations may be explained in different ways. Shiller (1981) and Summers (1986) suggest that "irrational fads" generate persistent deviations between prices and fundamentals and Daniel et al. (1998) explain positive deviations by investor overconfidence. Barberis and Thaler (2003) suggest that investors under-react to news about fundamentals in the short term, although they gradually incorporate them in the long run. Other studies show that heterogeneity in expectations (i.e. chartists, fundamentalists and noise traders), mimetic behavior and information asymmetry may help to explain the deviations and the existence of a nonlinear mean-reverting strength that leads stock prices to converge to fundamentals (see Poterba and Summers (1988), Fama and French (1988), Cecchetti et al. (1990), Manzan (2003), De Grauwe and Grimaldi (2006)), Jawadi (2006), and Boswijk et al. (2007)). In particular, Barberis et al. (1998) and Boswijk et al. (2007) develop two-regime models describing the dynamics of stock price deviations, while distinguishing a trend regime related to "trend follower" investors and a mean-reverting regime related to "fundamentalists". As a result, the authors show that nonlinearity characterizing the asset price adjustment dynamics can be explained by this heterogeneity in shareholder expectations.

Another approach focuses on arbitrage costs that have two components: the transaction costs and the risky arbitrage premium required due to the uncertainty characterizing the fundamentals. According to Anderson (1997), the transaction cost hypothesis alone could justify deviations and nonlinearity in stock price adjustment dynamics. Concerning the risky arbitrage hypothesis, Shleifer and Summers (1990) suggest that noise traders' behaviour may lead to greater fundamental mispricing of an asset. Perceived stock price deviations which represent risky arbitrage opportunities may not be 
arbitraged when expected gains are not large enough to compensate this risk, and this is a limitation of the arbitrage hypothesis. In this paper, we propose considering the total arbitrage cost as the sum of transaction costs and a risky arbitrage premium. Both transaction costs and risky arbitrage generate similar limit to arbitrage, to instantaneous stock price adjustment and thus to the efficiency hypotheses. With respect to the transaction costs only or the aversion to risky arbitrage only, taking the total arbitrage cost into account increases the possibility to observe nonlinearity in stock price adjustments. Considering heterogeneity in arbitrage costs, the main goal of this paper is to examine if, as expected, when prices are near fundamentals (i.e. the arbitrage cost is greater than expected gains) the deviations are durable, while when the prices are far from fundamentals (i.e. the arbitrage cost is lower than expected gains), the mean reversion is strongly activated.

As summarized hereafter, even though some recent papers such as Kian et al. (2007), Bali et al. (2008), Kim et al. (2009) have focused on the mean reversion in stock prices in a nonlinear framework, ${ }^{1}$ the literature associated with the issue of stock prices toward fundamentals is still relatively scarce, probably because of the difficulty involved in representing the fundamental value. In this paper, we propose an estimation of the fundamental value using the Dividend Discount Model (DDM), where the expected dividends are represented by a Smooth Transition Autoregressive Model (STAR). The deviation between stock price and fundamentals is modeled using a Smooth Transition Error Correction Model (STECM). The paper makes several contributions to the literature. First, while most previous studies do not investigate the adjustment toward fundamentals but rather toward some reference stock price index (e.g. the US index), this paper focuses on stock prices adjustment toward an explicit fundamental value. Second, the paper relates the econometric methodology of switching models to a formal theoretical model based on heterogeneous total arbitrage costs. Third, while most studies have focused on the American stock market, the present paper considers the G7 countries. Fourth, our proposed model takes into account the interdependences or contagion effects between stock markets. Finally, using indicators proposed by Peel and Taylor (2000) for the foreign exchange market, we identify the magnitude of under- and overvaluations and the speeds of adjustment for each

\footnotetext{
${ }^{1}$ For exchange rate market, see Yoon (2010) who identified a nonlinear mean-reversion toward the power parity (i.e. the fundamentals) using an ESTAR model.
} 


\section{2 - Arbitrage costs and stock price adjustments}

\section{1 - Theoretical framework: why do arbitrage costs cause nonlinearity in stock price adjustment?}

According to Shleifer and Summers (1990), noise trader behaviour may lead to enlarge the fundamental mispricing of assets. Perceived deviations of stock prices represent risky arbitrage opportunities, but these deviations may not be arbitraged when expected gains are not large enough to compensate the risk, and this is a limitation of the arbitrage hypothesis. Moreover, the existence of a distribution of the degrees of risk aversion across investors suggests that arbitrage increases according to the size of the fundamental mispricing, so that the arbitrage is more stabilizing when deviations are large, as suggested by Gallagher and Taylor (2001). Overall, this risky arbitrage hypothesis implies limit to arbitrage and may explain nonlinearity in stock price dynamics.

Concerning transaction costs, it is now well established that transaction costs may also generate such nonlinearities. Dumas (1992) suggests that the presence of transaction costs may generate nonlinear dynamics in foreign exchange rates. The author shows that these costs create two zones. In the first zone, called "the no trade band," arbitrages and adjustments are not active since the expected returns are lower than the transaction costs. This means that prices can continually deviate from their fundamental values. The deviations are left uncorrected as long as they are low with respect to transaction costs and they follow a near-unit root process in this area. Disequilibrium is only corrected in the second zone called the "exchange region", when price deviations and arbitrage profits are large enough to compensate for transaction costs. In this respect, stock price deviations are a white 
noise and stock prices can join their fundamentals with a convergence speed that depends on the size of the deviation. Following Dumas (1992), several studies have confirmed that transaction costs induce some delay and persistence in the dynamics of foreign exchange rates (Michael et al. (1997), Peel and Taylor (2000), De Grauwe and Grimaldi (2006)), interest rates (Anderson (1997), Liu (2001)) and stock prices (Manzan (2003), Boswijk et al. (2007)). These studies reject the linear, symmetrical, instantaneous and continuous adjustment hypothesis. It is worth noting that, for the stock market, these costs are far from negligible. According to reports by Elkins \& McSherry and Cherbonnier \& Vandelanoite (2008, p.89), direct transaction costs over 2005-2006, expressed as a \% of the amount of the transaction, reached 5.51, 10.23, 5.0, 6.58, 8.8, 10.65 and 5.9 for Germany, Canada, the USA (NYSE), the UK, Italy and Japan, respectively. It can be seen that transaction costs appear to be largely dependent on the country in question. For example, the USA and Japan showed the lowest transaction costs, while France took fifth position after Germany and the UK. ${ }^{2}$

Interestingly, Anderson (1997) proposed a model in which, due to transaction costs, the adjustment process of the US Treasury Bills rate toward its equilibrium value can be represented empirically by a STECM. The STECM was introduced by Granger and Teräsvirta (1993) and was more recently developed by Van Dijk et al. (2002). In this paper, we start with Anderson's model but adapt it to study stock market dynamics. In particular, and contrary to Anderson, we take into account both transaction costs and the risky character of arbitrage opportunities. Let $z_{t}=p_{t}-f_{t}$ be the actual deviation between the market $\log$-price $p_{t}$ of a portfolio of equities and its fundamental logvalue $f_{t}$ perceived by all investors. In the absence of transaction costs and arbitrage opportunities, any investor can make a profit from a stock price deviation. When $z_{t}=0$, there are no arbitrage opportunities, but when $z_{t}>0$ (respectively $z_{t}<0$ ), the portfolio is overvalued (respectively undervalued) and the incentive of arbitrage is based on expected profits. In this case, the adjustment process bringing the stock price toward fundamentals is classically continuous and linear with a constant speed of adjustment:

\footnotetext{
${ }^{2}$ Direct or explicit costs are largely composed of taxes, regulation costs and other commissions. They generally depend on the nature of the type of broker, the nature of the order, and the stock market.
} 


$$
\Delta z_{t}=-\rho z_{t-1}+\Phi(L) \Delta z_{t-1}+v_{t}
$$

where $\Phi(\mathrm{L})$ represents the distributed lag polynomial, $\Delta$ the first difference and $v_{t}$ a white noise.

Nevertheless, it can be seen that the existence of transaction costs and risk aversion reduces arbitrage opportunities. Let $\tau_{t}$ represent at time $t$ the sum of transaction costs and of a required premium due to the risky character of arbitrage opportunities resulting from uncertainty about the fundamental value perceived, both expressed in percent of the price. Accordingly, $\tau_{t}$ may be viewed as the total cost of arbitrage that we will hereafter call the "cost of arbitrage". Suppose in a first instance $\tau_{t}$ to be homogeneous across agents. When $z_{t}>\tau_{t}$ or when $z_{t}<-\tau_{t}$, the investor is incited to raise his/her detention of equities, while when $-\tau_{t}<z_{t}<\tau_{t}$, this arbitrage opportunity disappears. Here, the expected profits are clearly limited by arbitrage costs. It is worth noting that, in such a configuration, equation (1) is no longer adequate to reproduce the stock price adjustment dynamics, since it fails to replicate this discontinuity of arbitrages. In this case, the adjustment process takes into account both the no-trade zone and the arbitrage opportunity zone, and can be written as:

$$
\begin{array}{r}
\Delta z_{t}=-\rho \Omega\left(\left|z_{t-1}\right|\right) z_{t-1}+\Phi(L) \Delta z_{t-1}+\varepsilon_{t} \\
\text { where }: \Omega\left(\left|z_{t-1}\right|\right)=1 \quad \text { if }\left|z_{t-1}\right|>\tau_{t} \\
\Omega\left(\left|z_{t-1}\right|\right)=0 \text { if }\left|z_{t-1}\right| \leq \tau_{t}
\end{array}
$$

where $0<\Omega()<$.1 represents a transition function, allowing us to characterize which regime of the adjustment process holds at each date.

Moreover, stock market transaction costs are heterogeneous since they depend on many factors such as the amount of the transaction, the investor type, etc. ${ }^{3}$ The appreciation of risk associated with arbitrage opportunities is also agent-dependant since risk aversion is an individual

\footnotetext{
${ }^{3}$ In particular, spreads between transaction costs supported by individual investors and those supported by institutional investors contribute to heterogeneity.
} 
preference parameter. These disparities between individual transaction costs and individual appreciation of arbitrage risk may generate different arbitrage thresholds, so that the model (2) is no longer appropriate to describe the stock price adjustment. In this case, as shown by Anderson, the adjustment becomes gradual rather than sudden. Let $\tau_{j t}$ be the price of arbitrage associated with the purchase of a portfolio unity by investor $j$ at time $t$. A rational investor reacts to a price deviation only if $\tau_{j t}$ is such as $\tau_{j t}<z_{t-1}<-\tau_{j t}$. Let $H\left(\left|z_{t-1}\right|\right)$ be the cumulative density function of all investors' expenses, which represents the proportion of equities for which investors expect a benefit for time $t$ due to the price deviation. Formally, the introduction into equation (2) of heterogeneity in transaction costs and risky arbitrage premia implies the following adjustment process:

$$
\Delta z_{t}=-\rho H\left(\left|z_{t-1}\right|\right) z_{t-1}+\Phi(L) \Delta z_{t-1}+\varepsilon_{t}
$$

where the cumulative density function $H\left(\left|z_{t-1}\right|\right)$, ranging between 0 and 1 , is an exponential function defined as:

$$
H\left(\left|z_{t-1}\right|\right)=H\left(\tau_{t}\right)=1-\exp \left[-\beta \tau_{t}^{2}\right], \quad \beta>0 \text { and } \tau_{t} \geq 0
$$

with $\beta$ the transition speed and $\tau_{t}$ the average arbitrage costs at time $t$. Note that $H\left(\left|z_{t-1}\right|\right)$ equals $H\left(\tau_{t}\right)$ since, at the equilibrium price, expected gains resulting from price deviations $\left|z_{t-1}\right|$ just compensate the total cost of arbitrage $\tau_{t}$. The structural model given by equations (3) and (4) can be empirically estimated using a STECM, where $H\left(\tau_{t}\right)$ represents a smooth exponential transition function.

\section{2 - Empirical evidence of nonlinearity in stock price adjustment: surveying the literature}

Since the end of the 1980s, mean-reversion in stock prices toward fundamentals has received significant attention in the literature (Fama and French (1988), Poterba and Summers (1988), Lo and MacKinlay (1988)). The issue of the conditions in which this phenomenon operates is important 
because it contributes to define an optimal investment strategy. Indeed, when stock prices are meanreverting, momentum strategies are not relevant and returns may be expected to increase by shortselling high return equities and buying poor return equities. This is the contrarian trading/arbitrage (Balvers et al. (2000)), and suggests that the knowledge of the time pattern of the market price at any date is important for a rational investor. Although previous studies have separately identified meanreversion and momentum, Balvers and $\mathrm{Wu}$ (2006) propose a mixed model combining momentum and contrarian strategies at any date. For 18 developed equity markets (among them the US market), at a monthly frequency over the period 1969 to 1999, the authors show that this model outperforms both pure momentum and pure contrarian strategies. These results show the importance to knowing the type of dynamics characterising the stock market at a given date. To make stock return forecasts, when deviations are persistent within a central band but are mean-reverting outside, this suggests that a momentum strategy is preferable inside the band while a contrarian strategy would be better outside the band. Following this line, supposing that the real equilibrium value of equities is proportional to the real dividends (the coefficient of dividends may be constant or time-varying according to the hypothesis retained about the discount rate), Gallagher and Taylor (2001) analyse the speed of reversion of the US stock market by considering the deviation of the aggregate log dividend-price ratio from its equilibrium values over the period 1926-97 (quarterly data). Using an ESTAR-GARCH model, the authors show the existence of two expectation regimes, and provide evidence supporting the risky arbitrage hypothesis, the speed of the adjustment toward equilibrium varying according to the size of the deviation. Black et al. (2003) and Bohl (2003) also suggest strong evidence of nonlinear mean-reversion in the S\&P index, while, using a nonlinear mean-reversion test, the paper by Bali et al. (2008) confirms that the speed of mean-reversion is significantly higher during large falls on the US stock market, and suggests that knowledge of these dynamics can be useful in predicting stock returns. Boswijk et al. (2007) estimate a dynamic asset pricing model for the US stock market over the years 1871-2003 (S\&P annual data), characterized by heterogeneous agents where the fundamental value of equities is common knowledge (the authors suppose a constant risk-free rate and constant dividend growth), but where the agents have different beliefs about the persistence of stock price deviations from fundamentals, depending on transaction costs and expectation heterogeneity. According to this 
model, a strategy attracts more agents if it is performed relatively well in the recent past compared to other strategies. Using a STAR model, empirical results still reveal two expectation regimes: the fundamentalist regime (agents believe in mean-reversion of stock prices toward fundamentals) and the chartist regime (agents expect the deviations from the fundamental to continue). Interestingly, with regard to the general interpretation of these nonlinearities in explaining S\&P deviations, papers by Froot and Obstfeld (1991) and by Driffill and Sola (1998) compare the bubble hypothesis with the alternative of a threshold dynamic process. Both papers conclude in favor of the last hypothesis.

Although much of the research focuses on the US stock market, a growing literature about mean reversion of stock price relates to international stock markets. Considering a panel of 18 developed stock markets, and supposing that reversions are related from one national index to another and that the speed of reversion retains the same constant value for all markets, Balvers et al. (2000) found strong evidence of a mean reverting strength in the dynamics of stock price indexes. Using a linear model in which all the 17 emerging stock markets considered are still supposed to have the same constant speed of convergence, Chaudhuri and Wu (2004) confirm evidence of mean reversion in stock price indexes. In fact, these models are linear since they are based on the restrictive hypothesis of a constant reversion speed. Kian-Ping and Khim-Sen (2007) underline the risk of drawing the wrong inferences from mean reversion when the ADF test is applied to data governed by nonlinearity. Using the nonlinear stationary test proposed by Kapetanios et al. (2003), the authors reject the linearity hypothesis for all the Asian stock returns and find evidence of a nonlinear mean reverting pattern represented by a STAR model. ${ }^{4}$ More recently, Hyeongwoo et al. (2009) examined the G7 stock markets and tested whether deviations of each stock price from the reference US index are mean reverting. Using different transition functions leading to similar results (among them, the exponential function), the authors confirm strong evidence of nonlinear mean reversion over the period December 1969 to September 2007. Again, deviations toward the US index are found to be near a random walk within a central band but mean reverting outside. Although the authors do not refer to a formal

\footnotetext{
${ }^{4}$ In another way, Berdin and Hyde (2005) also use STAR models to capture nonlinearity in the cyclical character of stock price dynamics for eight countries (Belgium, Canada, France, Germany, Ireland, Japan, the United Kingdom and the United States). The authors show that the process describing the stock price adjustment toward fundamentals depends on the state of the economy (two regimes are considered: growth and recession). Using STAR models, Hasanov and Omay (2008) also show strong evidence in favor of nonlinear adjustment stock returns for the Athens and the Istanbul Stock markets.
} 


\section{3 - Stock price adjustment modeling in the G7 countries}

\section{1 - Fundamental value estimation}

In a world with perfect foresight and under the condition of transversality, the DDM can be expressed by the following recurrent equation defining the fundamental value $\bar{F}_{t}$ for a given country, this value corresponding to Shiller's "rational ex-post price":

$$
\bar{F}_{t+1}=\bar{F}_{t}\left(1+i_{o t}\right)-D_{t+1}
$$

where $i_{o t}$ is the one-period to maturity risk-free rate and $D_{t+1}$ the dividends distributed during the period $[t, t+1]$.

Considering now the fundamental value under the one-period ahead REH, the future dividends $D_{t+1}$ are replaced by the expected dividends $E_{t}\left(D_{t+1}\right)$, where $E_{t}($.$) is the expectation conditional to$ 
the information available at time $t$, the discount rate being defined as the sum of the risk-free rate $i_{o t}$ and the constant risk premium $\Phi_{o}$. The fundamental rational value is then given by the forward resolution of the following relation:

$$
F_{t+1}=F_{t}\left(1+i_{o t}+\Phi_{o}\right)-E_{t}\left(D_{t+1}\right)
$$

The generating process of $F_{t}$ is based on rational expectations that are revised at each date according to new information, and this is a less restrictive hypothesis than the REH at time $t$ for any future horizons often considered in the literature. The estimation of $F_{t}$ according to (6) requires not only the expected dividends time series but still an initial value $F_{o}$ at the beginning of the period and the value of the constant risk premium $\Phi_{o}$. To let the fundamental value explain the price as far as possible, these parameters are chosen to obtain the minimum sum of squared log-differences between prices and the fundamental values over the period of analysis. The fundamental value is estimated for the G7 countries (Canada, France, Germany, Italy, Japan, the United Kingdom and the United States) using monthly data over the period 1969-2005. Dividend series, which are computed using Price Indexes and Gross Indexes, and stock prices are obtained from the Morgan Stanley Capital International database. ${ }^{5}$ The monthly free-risk discount rate is given by the one month Monetary Market Rates (MMR), and the industrial production series (CSA) are obtained from the International Monetary Fund's International Financial Statistics. All data are expressed in local currencies. The Augmented Dickey-Fuller (ADF) and Phillips-Perron (PP) stationarity tests show that the log- G7 stock prices are $\mathrm{I}(1)$. Furthermore, the $\mathrm{G} 7$ stock return $^{6}$ distributions are found to be asymmetric and leptokurtic. This rejection of normality may indicate nonlinearity characterizing the dynamics of stock price.

\footnotetext{
${ }^{5}$ The gross index takes into account the dividend investment while the price index excludes it. All indexes are closing prices.

${ }^{6}$ The stock return is defined as the stock price logarithmic first difference plus the dividends yield.
} 
We carried out preliminary linearity tests (LM tests) introduced by Lukkonen et al. (1988) to test the null hypothesis of linearity against its alternative of nonlinearity. The implementation of these tests is described in Appendix 1 ( $§$ A-1.1). The results show that the dividend dynamics are nonlinear for all countries and highlight two significant regimes that characterize the dividend dynamics of the MSCI indexes (see Appendix 1, $\S \mathrm{A}-1.2$ ). This may be due to the coexistence of heterogeneous dividend policies and to changes in management strategies which can induce persistence and discontinuity in dividend dynamics. ${ }^{8}$ Interestingly, the LSTAR model is retained for Germany and the USA while an ESTAR model is estimated for the five other countries. The estimation results point to evidence of different regimes characterizing dividend dynamics. The estimated transition speed $(\hat{\gamma})$ is quite small for most indexes, indicating that the transition between these regimes is slow, due to the smooth character of the dividend series. When applying the misspecification tests proposed by Eitrheim and Teräsvirta (1996) to check the specification of the selected STAR model, we find that

\footnotetext{
${ }^{7}\left(\alpha_{0}, \alpha_{1}, \ldots, \alpha_{\mathrm{p}}\right)$ and $\left(\beta_{0}, \beta_{1}, \ldots, \beta_{\mathrm{p}}\right)$ are respectively the autoregressive coefficients in the first and second regime, $d$ is the lag parameter defining the transition variable $(d \geq 1), \gamma$ is the transition speed between the regimes, and $\mathrm{c}$ is the threshold parameter. $\Omega$ (.) is the transition function which is continuous and bounded between 0 and $1 . \Omega($ (.) is either logistic $(\Omega(\Delta I D t-d, \gamma, c)=(1+\exp \{-\gamma(\Delta I D t-d-c)\}-1, \gamma>0) \quad$ or $\quad$ exponential. $\left(\Omega(\Delta D t-d, \gamma, c)=1-\exp \left\{\gamma(\Delta I D t-d-c)^{2}\right\}, \gamma>0\right)$. It implies respectively a Logistic STAR (LSTAR) model or an Exponential STAR (ESTAR) model.

${ }^{8}$ For more explanations about nonlinearity characterizing dividend dynamics, see Jawadi (2009).
} 
residual sets have white noise properties, suggesting that representing $E_{t}\left(D_{t+1}\right)$ by a STAR model is in line with the REH.

After replacing $E_{t}\left(D_{t+1}\right)$ in the equation (6) by the estimated values of the appropriate STAR model (7), the initial values $F_{0}$ and $\Phi_{o}$ were chosen in the interval $\left[P_{0^{-}} 50 \%, P_{0}+50 \%\right]$ and $[0 \%, 8 \%]$ respectively in order to minimize $Q=\sum_{t=1}^{T}\left(p_{t}-f_{t}\right)^{2}$, where $p_{t}$ and $f_{t}$ are the log-values of price and fundamental value respectively, while $T$ indicates the number of observations. Estimates for $F_{0}$ and $\Phi_{o}$ given in table 2.

Table 2 - Initial fundamental values and risk premia estimates

\begin{tabular}{|l|l|l|l|l|l|l|l|}
\hline & Germany & Canada & USA & France & UK & Italy & Japan \\
\hline$\hat{\mathrm{F}}_{0}$ & 73.11 & 80.32 & 85.12 & 72.57 & 86.13 & 57.25 & 129.15 \\
\hline $\mathrm{P}_{0}$ & 100 & 100 & 100 & 103.67 & 100 & 80.51 & 100 \\
\hline$\hat{\Phi}_{O}$ & $3.8 \%$ & $4.8 \%$ & $5.4 \%$ & $3.95 \%$ & $4.29 \%$ & $6.01 \%$ & $6.58 \%$ \\
\hline
\end{tabular}

Note: $\mathrm{P}_{0}$ and $\hat{\mathrm{F}}_{0}$ are the initial values of observed price and of the fundamental value respectively, while $\hat{\Phi}_{O}$ is the risk premium estimate.

We note that, apart from Japan, all the price indexes were overvalued at the beginning of the period. Otherwise, the risk premium values seem realistic since the G7 premia average is about 5\% per year, which is coherent with the values obtained in the literature (among others, see Mehra and Prescott (1985), Siegel (1992), Cochrane (1997) and Pastor and Stambaugh (2000)). Figures presented in Appendix 2 show that the fundamental values are smooth in comparison with market prices for all seven countries, and this property is in accordance with the results proposed by Manzan (2003) and Boswijk et al. (2007). ${ }^{9}$ This feature means stock prices are often last away from their fundamentals for a long time, as underlined by Black et al. (2003) and Manzan (2003).

\footnotetext{
${ }^{9}$ The smooth character of fundamental values is implied by the DDM, not by the STAR model used to determine the expected dividend. Indeed, according to the DDM, the fundamental value is the sum of discounted future dividends, this sum leading to formally removing the short term movements in dividend and interest rate.
} 


\section{2 - Modeling stock price deviations with a STECM}

In a frictionless market and in the absence of arbitrage costs in particular, stock price adjustment is symmetrical, continuous and characterized by a constant speed of adjustment (see $\S 2.1$ ). A linear error correcting model (LECM) is therefore appropriate:

$$
\Delta z_{t}=k+\rho z_{t-1}+\sum_{i=1}^{p} \phi_{i} \Delta z_{t-i}+\varepsilon_{t}
$$

where $\rho$ characterizes the intensity of the stock price mean-reversion mechanism while $\varepsilon_{t}$ is a white noise. However, when the stock market is not frictionless, the LECM cannot describe stock price adjustment. In particular, arbitrage costs induce discontinuities in arbitrages and imply a nonlinear mean reversion phenomenon with a time-varying speed. Moreover, as shown in $\S 2.1$, when arbitrage costs are heterogeneous, the relevant model is a STECM. Introduced by Granger and Teräsvirta (1993), Van Dijk and Franses (2000) and Van Dijk et al. (2002), the STECM defines an adjustment process that depends on the sign (LSTECM) or size (ESTECM) of the deviation. Let $z_{t}=p_{t}-f_{t}$ be the relative deviation, where $p_{t}$ and $f_{t}$ are the log-values of price and the fundamentals, respectively. The general expression of a STECM is given as:

$$
\Delta z_{t}=k^{\prime}+\rho_{1} z_{t-1} \times\left[1-\Omega\left(\gamma, z_{t-d}, c\right)\right]+\rho_{2} z_{t-1} \times \Omega\left(\gamma, z_{t-d}, c\right)+\sum_{i=1}^{p} \phi_{i} \Delta z_{t-i}+\mu_{t}
$$

where $\rho_{1}$ and $\rho_{2}$ are the adjustment coefficients in the first and second regime respectively, $z_{t-1}$ is the lagged error-correction term, $z_{t-d}$ is the transition variable, $\phi_{i}$ are the AR parameters, $\Omega($.$) is the$ transition function and $\mu_{t} \rightarrow \mathrm{N}\left(0, \sigma_{\mu}{ }^{2}\right)$ is an error term.

It is worth noting that relationship (9) corresponds to Anderson's model (see (3) and (4)) if the transition function $\Omega($.$) is an exponential function and if the conditions k^{\prime}=\rho_{1}=c=0$ and $\phi_{i}=0$ $\forall i=2, \ldots, p$ hold. ${ }^{10}$ For $\Omega()=$.0 or $\Omega()=$.1 , the STECM (9) leads to the LECM (8). For the values of $\Omega($.$) ranging between 0$ and 1 , the adjustment is gradual rather than abrupt and its speed depends on

\footnotetext{
${ }^{10}$ For more details about these conditions, see equations (10) and (11).
} 
the size or the sign of the deviation: the larger the deviation, the stronger the tendency to move back to zero. This implies that even though $\rho_{l} \geq 0, \rho_{2}$ and $\left(\rho_{1}+\rho_{2}\right)$ should be strictly negative and the linear adjustment term $\rho$ must belong to the interval $\left[\rho_{l}, \rho_{l}+\rho_{2}\right]$ in order to comply with a nonlinear meanreversion process in stock prices (see Michael et al. (1997) among others). In the central regime, when the deviations are small, $z_{t}$ is close to a unit root process approaching a random walk $\left(z_{t} \rightarrow \mathrm{I}(1)\right)$, and may also demonstrate explosive behavior (when $\rho_{l} \geq 1$ ). In this regime, the deviations are persistent and stock prices can remain distant from their fundamentals for a long time. On the other hand, in the outer regimes, when deviations are large enough to pay for arbitrage costs, the process would be mean-reverting with a convergence speed that depends on the deviation size, and $z_{t}$ may approach a white noise. Furthermore, for each date, the adjustment process is described by a combination of the two adjustment patterns weighted by the transition function $\Omega_{t}$ and scaled by the coefficients $\rho_{l}$ and $\rho_{2}$. The greater the value of $\rho_{2}$ relative to $\rho_{1}$, the larger stock price deviations will be. Note that such behavior can escape from the conventional linear cointegration framework in the sense that $\mathrm{H}_{0}: \rho=0$ (i.e. LECM) may not be rejected even though stock prices are nonlinearly mean-reverting (i.e. $\left(\rho_{l}+\right.$ $\left.\rho_{2}\right)<0$ in the STECM). Conventional cointegration tests thus appear to be relatively ineffective in the presence of market frictions (see Taylor et al. (2001)). In fact, what appears important is testing the linear adjustment hypothesis against its alternative of nonlinearity and testing the cointegration hypothesis in a nonlinear framework by using nonlinear cointegration tests.

Before moving on to the nonlinear adjustment tests, in line with Peel and Taylor (2000), we now consider three hypotheses leading to a restricted specification of the STECM which have not previously been considered for stock markets:

$$
\begin{aligned}
& H_{0}^{a}: k^{\prime}=c=0, \\
& H_{0}^{b}: \rho_{1}+\rho_{2}=-1 / H_{0}^{a}, \\
& H_{0}^{c}: \rho_{1}=0 \text { s.t. } H_{0}^{a} \text { and } H_{0}^{b}
\end{aligned}
$$


Under these conditions, the equation (10) may be simplified to:

$$
\Delta z_{t}=-z_{t-1} \times \Omega\left(\gamma, z_{t-d}\right)+\sum_{i=1}^{p} \phi_{i} \Delta z_{t-i}+\mu_{t}
$$

The equation (11) is in conformity with the theoretical relation prevailing when arbitrage costs are heterogeneous (see above, (3) and (4)): stock price deviations are characterized by two regimes, namely, a random walk in the central regime (when arbitrage costs are larger than expected arbitrage gains) and a white noise in the outer regimes (when arbitrage costs are smaller than expected arbitrage gains). Furthermore, as it is shown below, these hypotheses enable us to compute two indicators proposed by Peel and Taylor (2000), the first giving the magnitude of under- and overvaluation of stock prices per date, and the second a measure per date of the speed of convergence between stock prices and fundamentals. In practice, both the unconstrained STECM (9) and the constrained STECM (11) have been estimated independently in order to test the restrictive hypotheses $\left(H_{0}^{a}, H_{0}^{b}, H_{0}^{c}\right)$ by using a likelihood ratio test.

\section{3 - Empirical relevance of the STECM specification}

To be defined, the STECM specification requires both the form of the transition function $\Omega($.) and of the basic linear model (LECM) from which regimes can be deduced. Concerning the linear model, in order to capture the interdependence or contagion between stock markets, we introduce the current and lagged US stock price deviations in the LECM as an exogenous variable in the adjustment process of the other G7 countries. The German (respectively French) deviations are also introduced for France (respectively Germany) to capture the interdependences or contagion between these two markets. In the same way, the Japanese deviations are introduced in the US stock price adjustment equation. Moreover, change in the domestic risk-free interest rate is retained as an exogenous variable in the model to capture a possible liquidity effect while rate of growth in the domestic industrial production is also introduced to capture a possible influence of the economic activity. Formally, the equation (8) has been extended for each country as follows: 


$$
\begin{aligned}
& \Delta z_{t}^{l}=k+\rho z_{t-1}+\sum_{i=1}^{p} \phi_{i} \Delta z_{t-i}^{l}+\sum_{j=0}^{p} \alpha_{j} \Delta z_{t-j}^{U S A}+\sum_{j=0}^{p} \alpha_{j}^{\prime} \Delta z_{t-j}^{F}+\sum_{j=0}^{p} \alpha_{j}^{\prime \prime} \Delta z_{t-j}^{G}+ \\
& +\sum_{j=0}^{p} \beta_{j} \Delta z_{t-j}^{J}+\sum_{j=0}^{p} \theta_{j} \Delta i_{0, t-j}^{l}+\sum_{j=0}^{p} \theta_{j}^{\prime} \Delta q_{t-j}^{l}+\varepsilon_{t}^{l}
\end{aligned}
$$

where $\mathrm{z}_{\mathrm{t}}^{\mathrm{USA}}, \mathrm{z}_{\mathrm{t}}^{\mathrm{F}}, \mathrm{z}_{\mathrm{t}}^{\mathrm{G}}$ and $\mathrm{z}_{\mathrm{t}}^{\mathrm{J}}$ are the US, French, German and Japanese stock price deviations respectively. $l=$ USA, France (F), Germany (G), United Kingdom (UK), Canada (Ca), Italy (I) and Japan $(\mathrm{J})$. For $l=\mathrm{USA}, \alpha_{j}=\alpha_{j}^{\prime}=\alpha_{j}^{\prime \prime}=0, \forall j$. For $l=\mathrm{F}, \alpha_{j}^{\prime}=\beta_{j}=0, \forall j$. For $l=\mathrm{G}$, $\beta_{j}=\alpha_{j}^{\prime \prime}=0, \forall j$. For $l=\mathrm{UK}=\mathrm{Ca}=\mathrm{I}=\mathrm{J}, \alpha_{j}^{\prime}=\alpha_{j}^{\prime \prime}=\beta_{j}=0, \forall j . i_{0}$ is the risk-free interest rate and $q_{t}$ is the log-index of industrial production.

Many specifications have been tested to determine the number of lags, using the AIC, BIC, Ljung-Box Statistics and the autocorrelation functions. As a result, we retain $p=1$ for Germany, the USA, France, Italy and Japan; $p=2$ for the UK and $p=3$ for Canada. The LECMs (12) are estimated by the OLS and the results are given in Appendix 3. Since contemporary values of residuals $\varepsilon_{t}^{l}$ for all seven countries are found to be insignificantly correlated, it was not necessary to estimate the seven equations as a system. ${ }^{11}$ Our results show that most of the AR parameters are statistically significant at $5 \%$ or $10 \%$. The adjustment coefficient $\hat{\rho}$ is negative and statistically significant, suggesting a mean reversion phenomenon in stock prices for all countries, apart from the US and Italy. For these last two countries, the rejection only concerns the strong hypothesis of a linear mean reversion and then leaves entire the possibility of a nonlinear influence of the error correction term. In addition, an interdependence or contagion effect is identified at the 5\% level, since the US market has a strong positive effect on all the other stock markets. A mutual contagion effect is also shown respectively between German and French and between US and Japanese stock markets. Otherwise, as expected with the liquidity effect hypothesis, changes in short-term interest rate have a negative effect on

\footnotetext{
${ }^{11}$ We nevertheless applied an SUR system estimate: estimates were insignificantly different from those obtained with the OLS. This result confirms that the seven equations can be estimated independently.
} 
changes in the deviations for all countries, while changes to industrial production have a positive delayed effect for Canada, the USA, the UK and Japan.

Because the linear modeling and usual unit root tests are less powerful when data are generated by a nonlinear process, we used "mixing tests", which are relevant for time series that are stationary but generated by a nonlinear process characterizing different types of behavior. In particular, several mixing tests were developed to investigate nonlinearity and nonstationarity hypotheses for time series. ${ }^{12}$ Among these tests, the KPSS test by Kwiatkowski et al. (1992) and the R/S test by Lo (1991) were applied to check the mixing and nonlinear cointegration hypotheses. Both tests consider the null hypothesis of "mixing" or short-range dependence against the alternative of "non-mixing." For the KPSS test, Schwert (1989) suggests two values for the truncation parameter:

$$
l_{4}=\operatorname{int}\left[4\left(\frac{T}{100}\right)^{\frac{1}{4}}\right] \text { and } l_{12}=\operatorname{int}\left[12\left(\frac{T}{100}\right)^{\frac{1}{4}}\right]
$$

where $T$ is the number of observations and int[.] denotes the integer part. In performing the $R / S$ test, $q$ is determined as follows (Andrews, 1991):

$q_{t}=\left[K_{T}\right], \quad$ where $K_{T}=\left(\frac{3 T}{2}\right)^{\frac{1}{3}}\left(\frac{2 \hat{\rho}}{1-\hat{\lambda}^{2}}\right)^{\frac{2}{3}}, \quad\left[K_{T}\right]=\operatorname{int}\left(K_{T}\right)$ and $\hat{\lambda} \quad$ is the first-order autocorrelation coefficient. The results of both tests are reported in Table $3 .{ }^{13}$ The mixing hypothesis is accepted at $5 \%$ for Germany, the UK and Italy according to the KPSS and at $10 \%$ for France, while it is retained for all countries according to the R/S test. This suggests the existence of a cointegration relationship between stock prices indexes and their fundamentals and the existence of a nonlinear mean reversion.

\footnotetext{
${ }^{12}$ For more details about mixing tests and conditions, see Dufrénot and Mignon (2002).

${ }^{13}$ Using similar tests, Hasanov (2009) tests the weak efficiency form for the Australian and New Zealand stock markets
} 
Table 3 - Nonlinear cointegration using mixing tests

\begin{tabular}{|c|c|c|c|}
\hline & \multicolumn{2}{|c|}{ KPSS test } & R/S test \\
\hline countries & $\boldsymbol{l}_{\boldsymbol{4}}$ & $\boldsymbol{l}_{\boldsymbol{1 2}}$ & Andrews (q) \\
\hline Germany & 0.35 & 0.14 & 1.1 \\
\hline Canada & 0.57 & 0.25 & 1.3 \\
\hline USA & 1.02 & 0.42 & 1.4 \\
\hline France & 0.50 & 0.22 & 1.2 \\
\hline UK & 0.27 & 0.12 & 1.0 \\
\hline Italy & 0.22 & 0.10 & 1.5 \\
\hline Japan & 0.92 & 0.38 & \\
\hline
\end{tabular}

Note: statistics are described in the texte above the table.

In order to check for the nature of the nonlinear dependence, we will now turn to the relevance of the nonlinear stock price adjustment hypothesis. We applied the LM linearity tests where the transition variable is supposed to be the lagged deviation $z_{t-d}$ for $1 \leq d \leq 12$ months. ${ }^{14}$ Besides the standard LM linearity tests, we apply linearity tests that are robust to heteroscedasticity (Van Dijk et al. (2002)). According to these tests, the rejection of linearity implies that nonlinearity is relevant, hence suggesting the rejection of the one regime hypothesis.

Table 4 - $\mathrm{LM}_{3}$ linearity test

\begin{tabular}{|l|l|l|l|l|l|l|l|}
\hline Delay & Germany & Canada & USA & France & UK & Italy & Japan \\
\hline$p$ & 1 & 3 & 1 & 1 & 2 & 1 & 1 \\
\hline$\hat{d}$ & 10 & 2 & 6 & 2 & 1 & 6 & 10 \\
$p$-value & $(0.00)$ & $(0.00)$ & $(0.00)$ & $(0.00)$ & $(0.00)$ & $(0.00)$ & $(0.00)$ \\
\hline
\end{tabular}

Note: Table 4 gives the p-values. $p$ indicates the number of lags in the change of the deviation and $\hat{d}$ the optimal number of lags in the transition variable $z_{t-d .}$. For the nature of the LM3 test, see footnote (14).

\footnotetext{
${ }^{14}$ In line with Teräsvirta (1994) and recently Van Dijk et al. (2002), we applied several LM tests $\left(\mathrm{LM}_{1}, \mathrm{LM}_{2}, \mathrm{LM}_{3}, \mathrm{LM}_{3}^{\mathrm{e}}\right.$ and $\mathrm{LM}_{4}$ ) for all possible values of $\mathrm{d}: 1 \leq d \leq 12$. The optimal value of the delay parameter $\hat{d}$ is such that linearity is rejected the most strongly. Thus, $\hat{d}$ should maximize the LM statistics and minimize the p-values of the linearity tests. In practice, all tests unanimously support nonlinearity, so we focus only on the results of the $\mathrm{LM}_{3}$ test that is available to test linearity against both exponential and logistic STECMs.
} 
The results presented in table 4 show that the $\mathrm{LM}_{3}$ test strongly rejects the linearity hypothesis at $5 \%$ for the seven stock markets, and this conclusion is in accordance with that of Manzan (2003) and Boswijk et al. (2007). ${ }^{15}$ Although the optimal value of $d$ varies across the different countries ( $d=10$ for Germany and Japan, $d=2$ for Canada and France, $d=6$ for the USA and Italy, and $d=1$ for the $\mathrm{UK}$ ), the validity of the STECM to describe stock price adjustment suggests that the expected effects of heterogeneous arbitrage costs are not rejected. ${ }^{16}$

The last step in the STECM specification is the choice of transition function $\Omega($.$) . Even though$ several previous studies retained a priori an exponential function which is in line with the arbitrage cost hypothesis (i.e. Michael et al. (1997), Manzan (2003) and Boswijk et al. (2007)), we tested the ESTECM against the LSTECM on the basis of tests developed by Teräsvirta (1994) and Escribano and Jordă (1999). Table 5 gives the results for the unrestricted STECM.

\footnotetext{
${ }^{15}$ These authors only apply the standard LM linearity tests.

${ }^{16}$ We briefly describe the STECM methodology and LM tests. More details can be found in Van Dijk et al. (2002) and Jawadi (2006).
} 
Table 5 - Selecting the transition function $\Omega($.

\begin{tabular}{|c|c|c|c|c|c|c|c|}
\hline \multirow[t]{2}{*}{ Countries } & \multirow{2}{*}{$\begin{array}{l}\text { Delay parameter } \\
\hat{d} \\
\end{array}$} & \multicolumn{3}{|c|}{$\begin{array}{c}p \text {-values } \\
\text { (Teräsvirta tests) }\end{array}$} & \multicolumn{2}{|c|}{$\begin{array}{c}p \text {-values } \\
\text { (Escribano and } \\
\text { Jordă tests) }\end{array}$} & \multirow{2}{*}{\begin{tabular}{|c|} 
Conclusion \\
Model
\end{tabular}} \\
\hline & & $H_{03}$ & $\mathrm{H}_{02}$ & $H_{01}$ & $H_{0 L}$ & $\boldsymbol{H}_{0 E}$ & \\
\hline Germany & 10 & 0.09 & 0.01 & 0.00 & 0.00 & 0.001 & \begin{tabular}{|l} 
ESTECM \\
\end{tabular} \\
\hline Canada & 2 & 0.01 & 0.00 & 0.00 & 0.008 & 0.00 & ESTECM \\
\hline The USA & 6 & 0.0009 & 0.00 & 0.001 & 0.003 & 0.00 & \begin{tabular}{|l} 
ESTECM \\
\end{tabular} \\
\hline France & 2 & 0.15 & 0.008 & 0.04 & 0.002 & \begin{tabular}{|l|}
0.00 \\
\end{tabular} & \begin{tabular}{|l} 
ESTECM \\
\end{tabular} \\
\hline The UK & 1 & 0.00 & 0.00 & 0.01 & 0.00 & 0.00 & $\begin{array}{l}\text { ESTECM } \\
\text { or } \\
\text { LSTECM }\end{array}$ \\
\hline Italy & 6 & 0.21 & 0.002 & 0.54 & 0.007 & 0.00 & ESTECM \\
\hline Japan & 10 & 0.24 & 0.004 & 0.001 & 0.00 & 0.00 & $\begin{array}{l}\text { ESTECM } \\
\text { or } \\
\text { LSTECM }\end{array}$ \\
\hline
\end{tabular}

Note: Teräsvirta tests and Escribano \& Jordă tests allow to specify the transition function while testing whether it is exponential $\left(\Omega\left(z_{t-d}, \gamma\right)=1-\exp \left\{-\gamma\left(z_{t-d}\right)^{2}\right\}\right)$ or $\left.\operatorname{logistic} \Omega\left(z_{t-d}, \gamma\right)=\left(1+\exp \left\{-\gamma\left(z_{t-d}\right)\right\}\right)^{-1}\right) . \mathrm{H}_{01}, \mathrm{H}_{02}$ and $\mathrm{H}_{03}$ are the null hypotheses in Teräsvirta tests which are based on the Fisher statistic. $\mathrm{H}_{O L}$ and $\mathrm{H}_{O E}$ are the null hypotheses tested by Escribano and Jordă (1999) and correspond to the auxiliary regression of the linearity tests $\left(\mathrm{LM}_{3}\right.$ and $\left.\mathrm{LM}_{4}\right)$. More details about these tests and about the $\mathrm{H}_{01}, \mathrm{H}_{02}$ and $\mathrm{H}_{03}$ null hypotheses can be found in Van Dijk et al. (2002) and Jawadi (2006).

According to table 5, the ESTECM can be retained to describe the stock price adjustment for most of the countries since the $\mathrm{H}_{02}$ hypothesis is rejected more strongly than the $\mathrm{H}_{01}$ and $\mathrm{H}_{03}$ hypotheses. These results are as one would expect when arbitrage costs are heterogeneous. Although both models may be retained for the UK and Japan, while estimating these two models, the information criteria appear to conclude in favor of the ESTECM. As a result, the ESTECM is therefore retained for all the G7-MSCI indexes. 


\section{4 - ESTECM estimations for the G7 stock prices}

The non-restricted ESTECM (9) and the restricted ESTECM (11) are estimated by the NLS method, both models being augmented with exogenous variables as indicated in (12). We tested the $H_{0}^{a}, H_{0}^{b}, H_{0}^{c}$ restrictions (10) using the likelihood ratio $L R=2\left[L\left(\theta_{1}\right)-L\left(\theta_{0}\right)\right]$, where $L\left(\theta_{0}\right)$ and $L\left(\theta_{1}\right)$ are respectively the log-likelihood of the restricted and non-restricted STECM. The LR ratio follows a $\chi^{2}(q)$ distribution where $q$ is the number of constraints. The results reported in Table 6 show that, for the seven MSCI indexes, the $H_{0}^{a}, H_{0}^{b}$ and $H_{0}^{c}$ restrictions are statistically accepted at $5 \%$. According to this restricted specification of the ESTECM, arbitrage costs are implicitly captured at each date. Indeed, since the calculated value of the endogenous variable at time $t$ is a weighted average of the values corresponding to the outer and central regimes, the first regime (white noise) will appear to be dominant when the costs are smaller than the expected gains, while the second regime will appear to be dominant (random walk) when arbitrage costs are higher than expected gains. This property of the model is far more interesting than it appears at first sight since arbitrage costs are timevarying (for example, transaction costs tended to decrease during last years of the period).

Table 6 - Testing $H_{0}^{a}, H_{0}^{b}$ and $H_{0}^{c}$ restrictions with the Likelihood Ratio

\begin{tabular}{|l|l|l|l|l|l|l|l|}
\hline Countries & Germany & Canada & USA & France & UK & Italy & Japan \\
\hline $\mathbf{L R}^{\text {a }}$ & 0.8 & 0.79 & 0.85 & 0.58 & 0.12 & 0.79 & 0.28 \\
\hline $\mathbf{L R}^{\mathbf{b}}$ & 0.89 & 0.93 & 0.98 & 0.82 & 0.09 & 0.77 & 0.11 \\
\hline $\mathbf{L R}^{\mathbf{c}}$ & 0.93 & 0.74 & 0.97 & 0.90 & 0.08 & 0.67 & 0.80 \\
\hline
\end{tabular}

Note: the table gives the $p$-values issued from the $L R$ test.

The ESTECM estimates under $H_{0}^{a}, H_{0}^{b}$ and $H_{0}^{c}$ are reported in Table 7. The AR parameters are statistically significant at $5 \%$. There is strong evidence of contagion or interdependence between the stock markets. In particular, the current and lagged US stock price deviations significantly affect the stock price adjustment of the other countries. There is also significant interdependence between the French and German and between the US and Japanese stock markets. Furthermore, interest rate 
variations negatively affect the stock market deviations, while changes in industrial production have a significant positive influence for Japan (at 5\%) and the USA (at 10\%) only. The transition speed $\gamma$ is statistically significant at 5\% (10\% for the UK). The values of $\gamma$ are relatively low, hence confirming the hypothesis of a smooth transition. This implies that stock prices are nonlinearly mean-reverting with an adjustment speed that depends on the size of deviations from the fundamentals at each date. For small deviations, stock prices can remain a long time distant from their fundamentals, but, for large deviations, when deviations exceed the arbitrage costs, arbitrage becomes active and the prices quickly revert back to fundamentals. 
Table 7 - Restricted ESTECM estimates

\begin{tabular}{|c|c|c|c|c|c|c|c|}
\hline & Germany & Canada & USA & France & UK & Italy & Japan \\
\hline$p$ & 1 & 3 & 1 & 1 & 2 & 1 & 1 \\
\hline$\hat{d}$ & 10 & 2 & 6 & 2 & 1 & 6 & 10 \\
\hline$\hat{\gamma}$ & $\begin{array}{l}0.62 \\
(3.8)^{*}\end{array}$ & $\begin{array}{l}0.10 \\
(4.4)^{*}\end{array}$ & $\begin{array}{l}0.57 \\
(3.6)^{*}\end{array}$ & $\begin{array}{c}8.53 \\
(3.29)^{*}\end{array}$ & $\begin{array}{c}0.64 \\
(1.63)^{* *}\end{array}$ & $\begin{array}{l}9.94 \\
(2.7)^{*}\end{array}$ & $\begin{array}{c}7.65 \\
(2.18)^{*}\end{array}$ \\
\hline$\hat{\phi}_{1}$ & $\begin{array}{c}-0.06 \\
(-1.75)^{* *}\end{array}$ & $\begin{array}{c}-0.08 \\
(-1.63)^{* *}\end{array}$ & $\begin{array}{c}-0.03 \\
(-1.69)^{* *}\end{array}$ & $\begin{array}{c}0.06 \\
(2.1)^{*}\end{array}$ & $\begin{array}{c}-0.02 \\
(-0.44)\end{array}$ & $\begin{array}{l}0.14 \\
(2.9)^{*}\end{array}$ & $\begin{array}{c}-0.02 \\
(-1.63)^{* *}\end{array}$ \\
\hline$\hat{\phi}_{2}$ & - & $\begin{array}{l}-0.02 \\
(-1.1)\end{array}$ & - & - & $\begin{array}{l}-0.46 \\
(-9.7)^{*}\end{array}$ & - & - \\
\hline$\hat{\phi}_{3}$ & - & $\begin{array}{c}0.17 \\
(5.4)^{*}\end{array}$ & - & - & - & - & - \\
\hline$\hat{\alpha}_{0}$ & $\begin{array}{c}0.16 \\
(3.07)^{*}\end{array}$ & $\begin{array}{c}0.68 \\
(16.1)^{*}\end{array}$ & - & $\begin{array}{c}0.44 \\
(7.9)^{*}\end{array}$ & $\begin{array}{c}1.08 \\
(21.7)^{*}\end{array}$ & $\begin{array}{c}0.98 \\
(13.1)^{*}\end{array}$ & $\begin{array}{l}0.06 \\
(1.2) \\
\end{array}$ \\
\hline$\hat{\alpha}_{1}$ & $\begin{array}{c}0.12 \\
(2.4)^{*}\end{array}$ & $\begin{array}{l}0.16 \\
(2.9)^{*}\end{array}$ & - & - & $\begin{array}{l}-0.05 \\
(-0.9)\end{array}$ & $\begin{array}{c}0.38 \\
(5.08)^{*}\end{array}$ & $\begin{array}{c}0.35 \\
(6.07)^{*}\end{array}$ \\
\hline$\hat{\alpha}_{2}$ & - & - & - & - & $\begin{array}{c}0.37 \\
(6.2)^{*}\end{array}$ & $\begin{array}{c}0.42 \\
(5.8)^{*}\end{array}$ & - \\
\hline$\hat{\alpha}_{0}^{\prime}$ & $\begin{array}{l}0.19 \\
(3.6)^{*}\end{array}$ & - & - & - & - & - & - \\
\hline$\hat{\alpha}_{0}^{\prime \prime}$ & - & - & & $\begin{array}{c}0.9 \\
(20.4)^{*}\end{array}$ & - & - & - \\
\hline$\hat{\beta}_{0}$ & - & - & $\begin{array}{c}0.18 \\
(3.9)^{*}\end{array}$ & - & - & - & - \\
\hline$\hat{\theta}_{0}$ & $\begin{array}{c}-0.007 \\
(-1.73)^{* *}\end{array}$ & $\begin{array}{l}-0.01 \\
(-4.2)^{*}\end{array}$ & $\begin{array}{c}-0.03 \\
(-6.06)\end{array}$ & $\begin{array}{l}-0.02 \\
(-5.8)^{*}\end{array}$ & $\begin{array}{l}-0.005 \\
(-1.8)^{* *}\end{array}$ & $\begin{array}{c}-0.06 \\
(-10.3)\end{array}$ & $\begin{array}{l}-0.01 \\
(-2.3)^{*}\end{array}$ \\
\hline$\hat{\theta}_{0}^{\prime}$ & - & - & - & 3 & - & - & $\begin{array}{c}0.34 \\
(1.98)^{*}\end{array}$ \\
\hline$\hat{\theta}_{1}^{\prime}$ & - & & $\begin{array}{c}0.41 \\
(1.8)^{* *}\end{array}$ & - & - & - & - \\
\hline$\hat{\gamma} \times \sigma_{z}^{2}$ & 0.07 & 0.006 & 0.08 & 1.2 & 0.04 & 1.3 & 1.1 \\
\hline $\mathrm{ADF}(\mathrm{p})$ & $\begin{array}{l}-13.9^{*} \\
(p=0)\end{array}$ & $\begin{array}{l}-14.3^{*} \\
(p=0)\end{array}$ & $\begin{array}{l}-14.8^{*} \\
(p=0)\end{array}$ & $\begin{array}{l}-14.6^{*} \\
(p=0)\end{array}$ & $\begin{array}{c}-20.3^{*} \\
(p=0)\end{array}$ & $\begin{array}{l}-14.6^{*} \\
(p=0)\end{array}$ & $\begin{array}{l}-14.07^{*} \\
(p=0)\end{array}$ \\
\hline DW & 1.97 & 2.04 & 2.02 & 2.03 & 2.01 & 2.0 & 2.02 \\
\hline $\mathrm{Q}(4)$ & 0.12 & 0.6 & 2.07 & 1.5 & 0.95 & 4.6 & 2.2 \\
\hline $\mathrm{Q}(12)$ & 5.31 & 29.2 & 9.34 & 13.07 & 14.2 & 15.5 & 6.7 \\
\hline $\mathrm{ARCH}(\mathrm{q})$ & $\begin{array}{l}5.06^{*} \\
(q=1)\end{array}$ & $\begin{array}{c}10.8^{*} \\
(q=1)\end{array}$ & $\begin{array}{c}14.3^{*} \\
(q=1)\end{array}$ & $\begin{array}{c}0.55^{*} \\
(q=1)\end{array}$ & $\begin{array}{l}17.7^{*} \\
(q=1)\end{array}$ & $\begin{array}{c}7.9^{*} \\
(\mathrm{q}=1)\end{array}$ & $\begin{array}{c}18.8^{*} \\
(q=2)\end{array}$ \\
\hline $\begin{array}{c}\mathrm{Nb} \text {. of } \\
\text { iterations }\end{array}$ & 18 & 47 & 30 & 45 & 27 & 25 & 28 \\
\hline
\end{tabular}

Note: The values under the estimates are the t-value ratios. $\mathrm{Q}(4)$ and $\mathrm{Q}(12)$ are the Ljung-Box statistics. (*) and (**) indicate respectively the significativity at 5\% and 10\%. ADF and ARCH are the statistics of the ADF and ARCH tests. The estimated model is the equation (9) under hypotheses $H_{0}^{a}, H_{0}^{b}$ and $H_{0}^{c}$ and augmented by exogenous variables as in equation (12):

$$
\begin{aligned}
& \Delta z_{t}^{l}=-z_{t-1} \times \Omega\left(\gamma, z_{t-d}\right)+\sum_{i=1}^{p} \phi_{i} \Delta z_{t-i}^{l}+\sum_{j=0}^{p} \alpha_{j} \Delta z_{t-j}^{U S A}+\sum_{j=0}^{p} \alpha_{j}^{\prime} \Delta z_{t-j}^{F}+\sum_{j=0}^{p} \alpha_{j}^{\prime \prime} \Delta z_{t-j}^{G}+ \\
& +\sum_{j=0}^{p} \beta_{j} \Delta z_{t-j}^{J}+\sum_{j=0}^{p} \theta_{j} \Delta i_{0, t-j}^{l}+\sum_{j=0}^{p} \theta_{j}^{\prime} \Delta q_{t-j}^{l}+\mu_{t}^{l}
\end{aligned}
$$


Figures in Appendix 4 plot for the seven countires the estimated values of the transition functions (vertical axis) against the lagged values of the stock price deviations (horizontal axis). It can be seen that observations are distributed around the equilibrium value on the left and the right side, hence confirming the choice of the exponential function and the relevance of the regimes. Moreover, the shapes of the functions are sharper for France, Italy and Japan (i.e. the functions increase quickly with deviations), suggesting that the transition occurs faster in these countries compared to the others. Furthermore, for these countries, the transition functions sometimes reach the unity, indicating strong evidence of significant persistence. ${ }^{17}$ Finally, to check the validity of the ESTECM estimations under $H_{0}^{a}, H_{0}^{b}$ and $H_{0}^{c}$, three misspecification tests are applied: a test of residual autocorrelation, a test of parameter stability and a test of omitted linearity (Appendix 5). First, the results show that the residuals are independent for the seven stock markets. Second, the hypothesis of parameter stability is accepted at 5\% except for the UK. Third, applying the robust linearity tests to the residuals for different values of $d, 1 \leq d \leq 12$, we find that the nonlinearity is well captured by the ESTECM, except for the UK. Overall, these results confirm our ESTECM specification, although they suggest that there is a missing exogenous variable in the UK equation.

\section{5 - Gauging under- and overvaluation phases and mean reversion strengths}

To gauge the degree of the under- and overvaluation of stock prices and the mean reversion strength over time, we estimate the two indicators $\Pi(z t)$ and $\Psi(z t)$ proposed by Peel and Taylor (2000) for the foreign exchange market, but which has not yet been applied to stock markets. The first indicator is defined as follows:

$$
\Pi\left(z_{t}\right)=100 \times \Omega\left(z_{t}\right) \times \operatorname{sign}\left(z_{t}\right), \operatorname{sign}\left(z_{t}\right) \equiv \frac{z_{t}}{\left|z_{t}\right|}, \quad-100 \leq \Pi\left(z_{t}\right) \leq 100
$$

The use of $\Pi\left(z_{t}\right)$ is based on the property that the transition function $\Omega($.$) measures the$ magnitude of the deviation from equilibrium since it implies a low degree of mean reversion for small

\footnotetext{
${ }^{17}$ Overall, our results are in line with Shen et al. (2007) who used a nonlinear cointegration test to examine long-run symmetric equilibrium relationships between the Chinese Shanghai and Shenzhen stock markets. Their findings also show evidence of nonlinear mean reversion with time-varying adjustment speed.
} 
deviations and a high degree of mean reversion for large deviations. This is why, substituting $z_{t}$ to $z_{t-d}$ in the exponential function $\Omega($.$) , and affecting the sign of z_{t}$ to the latter, allows us to determine the magnitude of the under- or overvaluation at any date. The condition $\Pi\left(z_{t}\right) \rightarrow 0$ means that the stock price approaches the fundamental value, while $\Pi\left(z_{t}\right)>0$ (respectively $\left.\Pi\left(z_{t}\right)<0\right)$ implies that the stock price is overvalued (respectively undervalued).

The indicator of the mean reversion strength proposed by Peel and Taylor depends directly on the importance of the autoregressive component in the STECM, and it can be shown that it just equals one minus the transition function:

$$
\Psi\left(z_{t}\right)=1-\Omega\left(z_{t-d}\right), 0 \leq \Psi(z t) \leq 1
$$

When $\Psi\left(z_{t}\right)$ moves toward 1, the speed of adjustment decreases and $z_{t}$ converges toward a random walk. Conversely, when $\Psi\left(z_{t}\right)$ moves toward 0 , the speed of adjustment increases and $z_{t}$ converges toward a white noise.

Calculating these two indicators for the stock markets leads to interesting new results. The values of $\Pi\left(z_{t}\right)$ per date for the G7 stock markets are reported by the figures given in Appendix 6 . One can observe long durations and high magnitude of under - and overvaluation of the MSCI stock indexes over the period. The values per date of $\Psi\left(z_{t}\right)$ are reported in figures given in Appendix 7. ${ }^{18}$ The convergence speeds appear to be strongly time-varying, sometimes smooth and sometimes abrupt. The adjustment speeds often appear to be greater when the stock price deviations are large. The adjustment speeds tend to be higher during crises (i.e. 1973, 1979, 1987). For the US, our results confirm those of Boswijk et al (2007), showing that the S\&P500 index was poorly mean-reverting during the period 1990-95. Overall, the dynamics of $\Pi\left(z_{t}\right)$ and $\Psi\left(z_{t}\right)$ show that, at each date, stock

\footnotetext{
${ }^{18}$ Note that the average adjustment delay from prices to fundamentals is about 5 months for the seven countries. This average is given by the sum of the optimal values of $d$ for the G7-MSCI indexes divided by 7.
} 
price adjustment is highly dependant on the country considered. However, during the last years of the period, it can be seen that, for almost all the countries, stock prices are near the fundamental value, hence suggesting low expected profits. Although the fall in transaction costs has been a recognized fact during the last years of the period, it is not surprising to observe that the speed of adjustment tends to be slow or decreasing since increased risk of arbitrage and decreased expected profits may largely compensate the decrease in transaction costs. This may also be considered as the emergence of a new fundamentalist predominance phase, leading the stock markets back to the fundamentals.

\section{4 - Concluding remarks}

This paper analyses the G7 stock price adjustments toward fundamentals represented by the dividend discount model. Adjustments are viewed as an "on/off" threshold error-correction model which works only when stock price deviations exceed a threshold determined by the investors' arbitrage costs defined as the sum of transaction costs plus a risky arbitrage premium. We found strong evidence of nonlinear mean-reversion in the G7 stock price indexes since the adjustment speeds increase with the magnitudes of the deviations from fundamentals. The ESTECM proposed takes into account the interdependences or contagion effects between stock markets and shows that stock price deviations follow a process close to a random walk in the central regime where prices are close to fundamentals (i.e. arbitrage costs are higher than expected gains) while deviations approach a white noise process in the outer regimes (i.e. arbitrage costs are lower than expected gains). In accordance with the expected effects due to heterogeneous arbitrage costs, our results show that the transition from one regime to the other generally follows a smooth, although sometimes abrupt, pattern. Finally, the dynamics of stock price adjustment are highly dependent on the date and the country under consideration, and this result seems intuitive since both arbitrage costs and expected gains are magnitudes characterized by rather high volatility. 


\section{References}

Allen D.E., Yang W.200.) Do UK Stock Prices Deviate from Fundamentals?. Working Paper, ${ }^{\circ}$ 6027, Edith Cowan University Joodalup Campus.

Anderson H. M. 1997. Transaction Costs and Nonlinear Adjustment Towards Equilibrium in The US Treasury Bill Markets. Oxford Bulletin of Economics and Statistics, Vol.59, 465-484.

Andrews D. 1991. Heteroscedasticity and Autocorrelation Consistent Covariance Matrix Estimation, Econometrica, 59, pp.817-858.

Bali T.G, Demirtas K. O, Levy H. 2008. Nonlinear mean reversion in stock prices. Journal of Banking and Finance, 32(5), 767-782.

Balvers R., Wu, Y. 2006. Momentum and mean reversion across national equity markets. Journal of Empirical Finance, 13, 24-48.

Balvers R. Wu, Y., Gilliland, E. 2000. Mean reversion across national stock markets and parametric contrarian investment strategies. Journal of Finance, 745-72.

Barberis N., Shleifer A., Vishny R.W.1998. A Model of Investor Sentiment. Journal of Financial Economics, 49, 307-343.

Barberis N., Thaler R.H. 2003. A survey of Behavioral Finance. In Handbook of the Economics of Finance”, George M. Constantinides, Milton Harris, and Rene' Stultz editors. Elsevier Science, North Holland, Amsterdam.

Berdin D., Hyde S. 2005. Regime Changes in the Relationship between Stock Returns and the Macroeconomy. Working Paper (February), University of Manchester.

Black A., Fraser P., Groenewold N. 2003. US Stock Prices and Macroeconomic Fundamentals. International Review of Economics and Finance, $\mathrm{N}^{\circ} 12,345-367$.

Bohl M.T. 2003. Collapsing Bubbles in the US Stock Market. International Review of Economics and Finance, $\mathrm{N}^{\circ} 12,385-397$. 
Boswijk H.P., Hommes C.H., Manzan S. 2007. Behavioral Heterogeneity in Stock Prices. Journal of Economic Dynamic and Control, 31(6), 1938-1970.

Campbell J.Y., Shiller R. 2001. Valuation Ratios and the Long-Run Stock Market Outlook: An Update". NBER Working Paper 8282.

Cecchetti S.G., Lam P.S., Mark N.C. 1990. Mean Reversion in Equilibrium Asset Prices. American Economic Review, 80, 398-418.

Chaudhuri K., Wu, Y. 2004. Mean reversion in stock prices: evidence from emerging markets. Managerial Finance, 30, 22-37.

Cherbonnier F., Vandelanoite S. 2008. L'impact de la directive MIF sur la liquidité des marchés financiers. Revue de la stabilité financière, $\mathrm{N}^{\circ}$ 11, 83-103.

Cochrane J. H. 1997. Where is the Market Going? Uncertain Facts and Novel Theory. Economic Perspectives, Federal Reserve Bank of Chicago, Nov, 3-37.

Daniel K., Hirshleifer D., Subrahmanyam A. 1998. Investor Psychology and Security Market Underand Overreactions. The Journal of Finance, Vol.53, nº 6 , December, 1839-85.

De Grauwe P., Grimaldi M. 2006. Heterogeneity of Agents, Transaction Costs and the Exchange Rate. Journal of Economic Dynamics and Control, 29, pp.691-719.

Driffill J., Sola M. 1998. Intrinsic Bubbles and Regime-Switching., Journal of Monetary Economics, Vol.42, 357-373.

Dufrénot G., Mignon V. 2002. Recent Developments in Nonlinear Cointegration with Applications in Macroeconomics and Finance, Kluwer Academic Publishers, Boston.

Dumas B. 1992. Dynamic Equilibrium and the Real Exchange Rate in a Spatially Separated World. Review of Financial Studies, 5, 153-180.

Eitrheim O., Teräsvirta T. 1996. Testing the Adequacy of Smooth Transition Autoregressive Models. Journal of Econometrics, Vol. 74, 59-75.

Escribano A., Jordã O.1999. Improving Testing and Specification of Smooth Transition Regression Models. In Rothman P. (ed), Nonlinear Times Series Analysis of Economic and Financial Data, Boston: kluwer, 298-319. 
Fama E., French K.R. 1988. Dividend Yields and Expected, Stock Returns. Journal of Financial Economics, 43, 341-372.

Froot K.A., Obstfeld M. 1991. Intrinsic Bubbles: the Case of Stock Price. American Economic Review, December, 81(5), 1189-1214.

Gallagher L.A., Taylor M.P. 2001. Risky Arbitrage, Limits to Arbitrage and Nonlinear Adjustment in the Dividend-Price Ratio. Economic Inquiry, 39(4), 524-36.

Granger C.W.J., Terasvirta T. 1993. Modelling Nonlinear Economic Relationships, Oxford: Oxford University Press.

Hasanov, M. 2009. A note on efficiency of Australian and New Zealand stock markets. Applied Economics, 41 (2), 1466-4283.

Hasanov, M. and Omay, T. 2008. Nonlinearities in emerging stock markets: evidence from

$\begin{array}{llll}\text { Europe's two largest } & \text { emerging }\end{array}$

Applied Economics, 40 (20), 1466-4283.

Hyeongwoo K., Stern, L.V., Stern M. L .2009. Nonlinear mean reversion in the G7 stock markets. Applied Financial Economics, 19(5), 347-355.

Jawadi F. 2009. Essay in Nonlinear Modeling and Forecasting: Does Nonlinearity Help? Applied Financial Economics, 19, issue 16, 1329-1343.

Jawadi F. 2006. Nonlinear Stock price Adjsutment, PhD, University of Paris West Nanterre La Défense, France.

Jawadi F., Koubbaa Y. 2007. Dynamique non-linéaire des marchés boursiers du G7: Une application des modèles STAR. Finance, 28 (1), 29-74

Kapetanios G., Shin Y., Snell A. 2003. Testing for a Unit Root in the Nonlinear STAR Framework. Journal of Econometrics, 112, 359-79.

Kian-Ping L., Khim-Sen L.V. 2007. Nonlinear Mean Reversion in Stock Prices: Evidence from Asian Market. Applied Financial Economics Letters, 3(1), 25-29. 
Kim H., Stern L.V., Stern M. L. 2009. Nonlinear Mean Reversion in the G7 Stock Markets”, Applied Financial Economics, 19(5), 347-355.

Kwiatkowski D., Phillips P., Schmidt P., Shin Y. 1992. Testing the Null Hypothesis of Stationary Against the Alternative of a Unit Root: How Sure Are We that Economic Time Series Have a Unit Root?. Journal of Econometrics, 54, 159-178.

Liu Y. 2001. Modelling Mortgage Rate Changes with a Smooth Transition Error-Correction Model. Working Paper n²001-21, Bank of Canada.

Lo A., MacKinlay A. 1988. Stock Market Prices Do Not Follow Random Walks: Evidence from a Simple Specification Test. Review of Financial Studies, 1, 41-66.

Lo A. W. 1991. Long-Term Memory in Stock Market Prices. Econometrica, 59(5), 1279-1313.

Luukkonen R., Saïkkonen P., Teräsvirta T. 1988. Testing Linearity against Smooth Transition Autoregressive Models. Biometrika, 75 (3), 491-499.

Manzan S. 2003. Essays on Nonlinear Economic Dynamics, PhD Thesis, University of Amsterdam.

Mehra R., Prescott E.C. 1985. The Equity Premium: A Puzzle. Journal of Monetary Economics, 15, $145-62$.

Michael P., Nobay A. R., Peel D. A. 1997. Transaction costs and Nonlinear Adjustment in Real Exchange Rates: An Empirical Investigation. Journal of Political Economy. 105, 862-879.

Pastor L., Stambaugh R. 2000. The Equity Premium and Structural Breaks. NBER Working Paper, ${ }^{\circ}$ 7778.

Peel D. A., Taylor M. P. 2000. Nonlinear Adjustment, Long-run Equilibrium and Exchange Rate Fundamentals. Journal of International Money and Finance, 19, 33-53.

Poterba J. M., Summers L. H. 1988. Mean Reversion in Stock Prices: Evidence and Implications. Journal of Financial Economics, 22 (1), 27-59.

Schwert G. W. 1989. Tests for Unit Roots: A Monte Carlo Investigation. Journal of Business \& Economic Statistics, 7, pp.147-159. 
Shen, C, H., Chen, C., F., and Chen, L., H. 2007. An empirical study of the asymmetric cointegration relationships among the Chinese stock markets. Applied Economics, 39 (11), 1466-4283.

Shiller R. 1981. Do Stock Prices Move Too Much to be justified by Subsequent Changes in Dividends. The American Economic Review, 71 (3), 421-436.

Shleifer A., Summers L.H. 1990. The Noise Trader Approach to Finance. Journal of Economic Perspectives, 4, 19-33.

Siegel J.J. 1992. The Equity Premium: Stock and Bond Return Since 1802. Financial Analysts Journal, February, 28-38.

Summers L. M. 1986. Does the Stock Market Rationally Reflect Fundamental Values? The Journal of Finance, XLI (3), 591-601.

Taylor M.P., Peel D.A. and Sarno L. 2001. Nonlinear Mean-Reversion in Real Exchange Rates: Towards a Solution to the Purchasing Power Parity Puzzles. International Economic Review, 4, 10151041.

Teräsvirta T. 1994. Specification, Estimation and Evaluation of Smooth Transition Autoregressive Models. Journal of the American Statistical Association, 89, 208-218.

Van Dijk D., Teräsvirta T. and Franses P.H. 2002. Smooth Transition Autoregressive Models- A Survey of Recent Developments. Econometric Reviews, 21, 1-47.

Van Dijk, D., Frances P.H. 2000. Nonlinear Error Correction Models for Interest Rates in the Netherlands. in W.A. Barnett et al. (eds), Nonlinear Econometric Modeling, Cambridge University Press.

Yoon, G. (2010). Nonlinear mean-reversion to purchasing power parity: exponential smooth transition autoregressive models and stochastic unit root processes. Applied Economics, 42 (4), 1466-4283. 


\section{Appendix 1 - Estimating the expected dividends}

\section{A1.1 - Preliminary tests of linearity: methodology}

Below, we briefly describe linearity tests. Details of these tests may be found in Van Dijk et al. (2002). Formally, in equation (7), since $\Omega()=$.0 when $\gamma=0$, the linearity hypothesis can be expressed as $\mathrm{H}_{0}: \gamma=0$, and the linearity test consists of testing $\mathrm{H}_{0}$ against $\mathrm{H}_{1}: \gamma>0$. In order to apply this test, Luukkonen et al (1988) developed Lagrange Multiplier-type tests with a standard $\chi^{2}$ distribution under $\mathrm{H}_{0}$. However, in practice, the implementation of these tests yields some nuisance problems since the null hypothesis can be defined differently. ${ }^{19}$ To solve this problem, the authors proposed replacing the transition function by its Taylor approximation. For an exponential function, they show that the appropriate LM linearity test associated with the first-order of the auxiliary regression is based on the statistic $L M_{2}=\frac{T\left(S C R_{0}-S C R_{2}\right)}{S C R_{0}}$, where $S C R_{2}$ is the residual squared sum of nonlinear model and $S C R_{0}$ is that of the linear model under $\mathrm{H}_{0}$. The $L M_{2}$ statistic is asymptotically distributed as a $\chi^{2}(2(p+1))$. More recently, Escribano and Jorda (1999) showed that the first-order approximation of the exponential function is insufficient, and recommend using the second order Taylor approximation. Consequently, they developed another LM test. The statistic of this test is noted $L M_{4}$ and is also distributed as $\chi^{2}(4(p+1)) .{ }^{20}$ In practice, all the tests (five LM tests) are carried out to test the null of linearity for dividends against the alternative of nonlinearity. The tests are applied for several values of the delay parameter $(d)$. The optimal value of $d$ that defines the transition variable is the one where linearity is most strongly rejected.

\footnotetext{
${ }^{19}$ For more details, see Luukkonen et al (1988).

${ }^{20}$ For more details about these linearity tests, see Van Dijk et al. (2002), Jawadi and Koubbaa (2006) among others.
} 
A1.2 - STAR estimations of dividends (equation (7))

\begin{tabular}{|c|c|c|c|c|c|c|c|}
\hline & Germany & Canada & USA & France & UK & Italy & Japan \\
\hline$\alpha_{0}$ & $\begin{array}{l}0.06 \\
(0.9)\end{array}$ & $\begin{array}{l}-0.26^{a} \\
(-2.8)\end{array}$ & $\begin{array}{l}0.28^{\mathrm{a}} \\
(2.2)\end{array}$ & $\begin{array}{l}-0.006 \\
(-0.1)\end{array}$ & $\begin{array}{l}-0.008 \\
(-0.27)\end{array}$ & $\begin{array}{l}0.01 \\
(0.1)\end{array}$ & $\begin{array}{c}5.9 \mathrm{a} \\
(12.7)\end{array}$ \\
\hline$\alpha_{1}$ & $\begin{array}{l}0.08 \\
(1.1)\end{array}$ & $\begin{array}{l}0.9^{\mathrm{a}} \\
(2.1)\end{array}$ & $\begin{array}{c}-017^{\mathrm{a}} \\
(-10.8)\end{array}$ & $\begin{array}{l}-0.73^{\mathrm{a}} \\
(-7.9)\end{array}$ & $\begin{array}{l}-0.62^{\mathrm{a}} \\
(-4.6)\end{array}$ & $\begin{array}{l}0.08^{\mathrm{a}} \\
(2.3)\end{array}$ & $\begin{array}{l}-1.02^{\mathrm{a}} \\
(-5.7)\end{array}$ \\
\hline$\alpha_{2}$ & $\begin{array}{l}-0.002 \\
(-1.04)\end{array}$ & $\begin{array}{l}-0.27 \\
(-0.4)\end{array}$ & $\begin{array}{l}-3.5^{\mathrm{a}} \\
(-6.3)\end{array}$ & $\begin{array}{l}-0.71^{\mathrm{a}} \\
(-7.5)\end{array}$ & $\begin{array}{l}-0.78^{a} \\
(-7.3)\end{array}$ & $\begin{array}{l}-0.06^{\mathrm{a}} \\
(-2.3)\end{array}$ & $\begin{array}{l}-2.3^{\mathrm{a}} \\
(-6.8)\end{array}$ \\
\hline$\alpha_{3}$ & $\begin{array}{l}0.2^{\mathrm{b}} \\
(1.9)\end{array}$ & $\begin{array}{l}0.75 \\
(1.1) \\
\end{array}$ & $\begin{array}{l}-2.0^{\mathrm{a}} \\
(-3.6) \\
\end{array}$ & $\begin{array}{l}-0.82^{\mathrm{a}} \\
(-9.7) \\
\end{array}$ & $\begin{array}{l}-0.49^{\mathrm{a}} \\
(-4.3) \\
\end{array}$ & $\begin{array}{l}0.03 \\
(0.7) \\
\end{array}$ & $\begin{array}{l}-1.62^{\mathrm{a}} \\
(-13.9) \\
\end{array}$ \\
\hline$\alpha_{4}$ & $\begin{array}{l}0.01^{\mathrm{a}} \\
(2.1)\end{array}$ & $\begin{array}{c}-0.17 \\
(-0.28) \\
\end{array}$ & $\begin{array}{l}-1.7^{\mathrm{a}} \\
(-3.2)\end{array}$ & $\begin{array}{l}-0.64^{\mathrm{a}} \\
(-5.6)\end{array}$ & $\begin{array}{l}-0.52^{\mathrm{a}} \\
(-4.7)\end{array}$ & $\begin{array}{l}0.01 \\
(0.5)\end{array}$ & $\begin{array}{c}-1.6^{\mathrm{a}} \\
(-15.1)\end{array}$ \\
\hline$\alpha_{5}$ & $\begin{array}{c}-0.004 \\
(-1.2)\end{array}$ & $\begin{array}{l}1.5^{\mathrm{a}} \\
(2.2)\end{array}$ & $\begin{array}{l}-0.33 \\
(-0.7)\end{array}$ & $\begin{array}{l}-0.68^{\mathrm{a}} \\
(-6.9)\end{array}$ & $\begin{array}{l}-0.13 \\
(-1.2)\end{array}$ & $\begin{array}{l}-0.1^{\mathrm{a}} \\
(-3.3)\end{array}$ & $\begin{array}{l}0.41 \\
(1.3)\end{array}$ \\
\hline$\alpha_{6}$ & $\begin{array}{l}0.08^{\mathrm{a}} \\
(2.2)\end{array}$ & $\begin{array}{l}3.1^{\mathrm{a}} \\
(4.0)\end{array}$ & $\begin{array}{l}0.13 \\
(0.2)\end{array}$ & $\begin{array}{l}-0.95^{\mathrm{a}} \\
(-8.1)\end{array}$ & $\begin{array}{l}0.57^{\mathrm{a}} \\
(3.8)\end{array}$ & $\begin{array}{l}0.25^{\mathrm{a}} \\
(8.6)\end{array}$ & $\begin{array}{l}-0.69^{\mathrm{a}} \\
(-5.6)\end{array}$ \\
\hline$\alpha_{7}$ & $\begin{array}{l}-0.04 \\
(-0.7)\end{array}$ & $\begin{array}{l}-3.09^{\mathrm{a}} \\
(-4.1)\end{array}$ & $\begin{array}{l}0.39 \\
(0.8)\end{array}$ & $\begin{array}{l}-0.86^{\mathrm{a}} \\
(-7.3)\end{array}$ & $\begin{array}{l}0.44^{\mathrm{a}} \\
(2.8)\end{array}$ & $\begin{array}{l}-0.03 \\
(-0.5)\end{array}$ & $\begin{array}{l}-0.66^{\mathrm{a}} \\
(-3.7)\end{array}$ \\
\hline$\alpha_{8}$ & $\begin{array}{l}0.07 \\
(1.6) \\
\end{array}$ & $\begin{array}{l}1.02^{\mathrm{a}} \\
(3.5) \\
\end{array}$ & $\begin{array}{l}1.07^{\mathrm{a}} \\
(2.2)\end{array}$ & $\begin{array}{l}-0.84^{\mathrm{a}} \\
(-6.7)\end{array}$ & $\begin{array}{l}0.34^{\mathrm{a}} \\
(2.1)\end{array}$ & $\begin{array}{l}0.04^{b} \\
(1.8)\end{array}$ & $\begin{array}{c}1.7^{a} \\
(6.0)\end{array}$ \\
\hline$\alpha_{9}$ & $\begin{array}{l}0.11^{b} \\
(1.7)\end{array}$ & $\begin{array}{l}0.15^{\mathrm{b}} \\
(1.7)\end{array}$ & $\begin{array}{l}1.2^{\mathrm{a}} \\
(2.7)\end{array}$ & $\begin{array}{l}1.02^{\mathrm{b}} \\
(1.6)\end{array}$ & $\begin{array}{l}0.004 \\
(0.03)\end{array}$ & $\begin{array}{l}-0.11 \\
(-1.0)\end{array}$ & - \\
\hline$\alpha_{10}$ & $\begin{array}{l}0.09 \\
(1.3)\end{array}$ & - & $\begin{array}{c}1.6^{\mathrm{a}} \\
(2.9)\end{array}$ & $\begin{array}{c}-2.2^{\mathrm{a}} \\
(-10.7)\end{array}$ & $\begin{array}{l}-0.09 \\
(-0.7)\end{array}$ & $\begin{array}{l}0.02 \\
(0.4)\end{array}$ & - \\
\hline$\alpha_{11}$ & $\begin{array}{l}0.06^{b} \\
(1.9)\end{array}$ & - & $\begin{array}{l}0.59 \\
(1.5)\end{array}$ & $\begin{array}{l}-0.35^{\mathrm{a}} \\
(-2.1)\end{array}$ & $\begin{array}{l}-0.32^{a} \\
(-3.2)\end{array}$ & $\begin{array}{l}0.06 \\
(0.6)\end{array}$ & - \\
\hline$\alpha_{12}$ & $\begin{array}{l}0.05^{\mathrm{a}} \\
(7.5)\end{array}$ & - & $\begin{array}{l}- \\
-\end{array}$ & $\begin{array}{l}0.27^{\mathrm{a}} \\
(2.8)\end{array}$ & $\begin{array}{l}-0.16^{\mathrm{b}} \\
(-1.9)\end{array}$ & $\begin{array}{l}-2.1^{\mathrm{a}} \\
(-2.0)\end{array}$ & - \\
\hline$\beta_{0}$ & $\begin{array}{r}1.9^{\mathrm{a}} \\
(5.5)\end{array}$ & $\begin{array}{l}0.3^{\mathrm{a}} \\
(3.1)\end{array}$ & $\begin{array}{l}-0.26^{\mathrm{a}} \\
(-2.0)\end{array}$ & $\begin{array}{l}5.1^{\mathrm{a}} \\
(2.2)\end{array}$ & $\begin{array}{l}2.36^{\mathrm{a}} \\
(5.5)\end{array}$ & $\begin{array}{l}4.1^{\mathrm{a}} \\
(7.1)\end{array}$ & $\begin{array}{c}-5.8^{\mathrm{a}} \\
(-12.6)\end{array}$ \\
\hline$\beta_{1}$ & $\begin{array}{l}0.42^{\mathrm{a}} \\
(4.2)\end{array}$ & $\begin{array}{l}-2.0^{\mathrm{a}} \\
(-4.8)\end{array}$ & $\begin{array}{l}0.7^{\mathrm{a}} \\
(3.8)\end{array}$ & $\begin{array}{l}3.3^{\mathrm{a}} \\
(2.5)\end{array}$ & $\begin{array}{l}-1.06^{\mathrm{a}} \\
(-5.2)\end{array}$ & $\begin{array}{l}0.01^{\mathrm{a}} \\
(0.1)\end{array}$ & $\begin{array}{l}0.96^{\mathrm{a}} \\
(4.3)\end{array}$ \\
\hline$\beta_{2}$ & $\begin{array}{l}-0.31^{\mathrm{a}} \\
(-3.7)\end{array}$ & $\begin{array}{l}-0.99^{b} \\
(-1.7)\end{array}$ & $\begin{array}{c}2.5^{\mathrm{a}} \\
(-4.4)\end{array}$ & $\begin{array}{l}-1.9^{a} \\
(-0.9)\end{array}$ & $\begin{array}{c}-1.4 \\
(-0.6)\end{array}$ & $\begin{array}{l}0.04 \\
(0.2)\end{array}$ & $\begin{array}{c}2.4^{\mathrm{a}} \\
(6.8)\end{array}$ \\
\hline$\beta_{3}$ & $\begin{array}{c}0.1 \\
(1.1)\end{array}$ & $\begin{array}{l}-1.3^{b} \\
(-1.9)\end{array}$ & $\begin{array}{l}1.3^{\mathrm{a}} \\
(2.3)\end{array}$ & $\begin{array}{l}4.6^{\mathrm{a}} \\
(2.4)\end{array}$ & $\begin{array}{l}-1.7^{\mathrm{a}} \\
(-5.5)\end{array}$ & $\begin{array}{l}-2.3^{\mathrm{a}} \\
(-5.3)\end{array}$ & $\begin{array}{c}1.6^{\mathrm{a}} \\
(13.8)\end{array}$ \\
\hline$\beta_{4}$ & $\begin{array}{l}-0.43^{\mathrm{a}} \\
(-5.2)\end{array}$ & $\begin{array}{c}-0.3 \\
(-0.5)\end{array}$ & $\begin{array}{l}1.0^{b} \\
(1.7)\end{array}$ & $\begin{array}{l}-4.1^{\mathrm{a}} \\
(-1.6)\end{array}$ & $\begin{array}{c}-1.6^{\mathrm{a}} \\
(-4.4)\end{array}$ & $\begin{array}{l}-1.1^{\mathrm{a}} \\
(-5.8)\end{array}$ & $\begin{array}{c}1.7^{\mathrm{a}} \\
(15.1)\end{array}$ \\
\hline$\beta_{5}$ & $\begin{array}{l}-0.12 \\
(-1.3)\end{array}$ & $\begin{array}{l}-2.0^{\mathrm{a}} \\
(-2.7)\end{array}$ & $\begin{array}{l}-0.34 \\
(-0.7)\end{array}$ & $\begin{array}{c}0.21 \\
(0.22)\end{array}$ & $\begin{array}{c}-2.03^{\mathrm{a}} \\
(-5.1)\end{array}$ & $\begin{array}{l}0.06 \\
(0.2)\end{array}$ & $\begin{array}{c}-0.4 \\
(-1.2)\end{array}$ \\
\hline$\beta_{6}$ & $\begin{array}{l}-0.25^{a} \\
(-2.4)\end{array}$ & $\begin{array}{l}-3.7^{a} \\
(-4.6)\end{array}$ & $\begin{array}{l}-0.59 \\
(-1.1)\end{array}$ & $\begin{array}{l}1.5^{\mathrm{b}} \\
(1.8)\end{array}$ & $\begin{array}{c}-2.4^{\mathrm{a}} \\
(-7.4)\end{array}$ & $\begin{array}{c}0.1 \\
(0.4)\end{array}$ & $\begin{array}{c}1.4^{\mathrm{a}} \\
(10.2)\end{array}$ \\
\hline$\beta_{7}$ & $\begin{array}{l}-0.09 \\
(-1.0)\end{array}$ & $\begin{array}{l}-3.4^{\mathrm{a}} \\
(-4.4)\end{array}$ & $\begin{array}{l}-0.84 \\
(-1.5)\end{array}$ & $\begin{array}{l}1.8^{\mathrm{a}} \\
(2.1)\end{array}$ & $\begin{array}{l}-2.5^{a} \\
(-7.9)\end{array}$ & $\begin{array}{l}-3.8^{\mathrm{a}} \\
(-8.7)\end{array}$ & $\begin{array}{l}0.86^{\mathrm{a}} \\
(3.8)\end{array}$ \\
\hline$\beta_{8}$ & $\begin{array}{c}-0.33^{\mathrm{a}} \\
(2.6)\end{array}$ & $\begin{array}{l}-1.3^{\mathrm{a}} \\
(-4.2)\end{array}$ & $\begin{array}{l}-1.7^{\mathrm{a}} \\
(-3.3)\end{array}$ & $\begin{array}{c}1.1 \\
(1.3)\end{array}$ & $\begin{array}{l}-2.1^{\mathrm{a}} \\
(-8.1)\end{array}$ & $\begin{array}{l}-0.03 \\
(-0.1)\end{array}$ & $\begin{array}{l}-1.6^{\mathrm{a}} \\
(-5.8)\end{array}$ \\
\hline$\beta_{9}$ & $\begin{array}{l}0.46^{\mathrm{a}} \\
(4.9)\end{array}$ & $\begin{array}{l}-0.08 \\
(-0.3)\end{array}$ & $\begin{array}{l}-1.8^{\mathrm{a}} \\
(-3.6)\end{array}$ & $\begin{array}{c}-0.7 \\
(-0.8)\end{array}$ & $\begin{array}{l}-1.6^{\mathrm{a}} \\
(-6.6)\end{array}$ & $\begin{array}{l}7.3^{\mathrm{a}} \\
(3.8)\end{array}$ & - \\
\hline$\beta_{10}$ & $\begin{array}{l}-0.26 \\
(-0.9)\end{array}$ & - & $\begin{array}{l}-1.9^{\mathrm{a}} \\
(-3.3)\end{array}$ & $\begin{array}{l}2.1^{\mathrm{a}} \\
(2.4)\end{array}$ & $\begin{array}{c}-1.9^{\mathrm{a}} \\
(-7.1)\end{array}$ & $\begin{array}{c}-1.2^{\mathrm{a}} \\
(-12.8)\end{array}$ & - \\
\hline$\beta_{11}$ & $\begin{array}{l}-0.09 \\
(-0.3)\end{array}$ & - & $\begin{array}{l}-0.8^{\mathrm{a}} \\
(-2.0)\end{array}$ & $\begin{array}{c}0.3 \\
(0.4)\end{array}$ & $\begin{array}{l}-1.1^{\mathrm{a}} \\
(-6.4)\end{array}$ & $\begin{array}{c}-0.17^{\mathrm{a}} \\
(-1.0)\end{array}$ & - \\
\hline$\beta_{12}$ & $\begin{array}{l}0.29^{\mathrm{a}} \\
(2.0)\end{array}$ & - & - & $\begin{array}{l}-0.5^{\mathrm{b}} \\
(-1.7)\end{array}$ & $\begin{array}{c}-0.08^{b} \\
(-1.8)\end{array}$ & $\begin{array}{l}0.32^{b} \\
(1.8)\end{array}$ & - \\
\hline$\gamma$ & $\begin{array}{l}5.3^{\mathrm{a}} \\
(2.8)\end{array}$ & $\begin{array}{l}1.43^{\mathrm{a}} \\
(6.9)\end{array}$ & $\begin{array}{l}0.24^{\mathrm{a}} \\
(2.5)\end{array}$ & $\begin{array}{l}5.2^{\mathrm{a}} \\
(2.8)\end{array}$ & $\begin{array}{l}0.17^{\mathrm{a}} \\
(4.9)\end{array}$ & $\begin{array}{l}0.16^{\mathrm{a}} \\
(3.8)\end{array}$ & $\begin{array}{l}66.4^{\mathrm{a}} \\
(5.8)\end{array}$ \\
\hline $\mathrm{c}$ & $\begin{array}{c}0.78^{\mathrm{a}} \\
(14.8)\end{array}$ & $\begin{array}{l}-0.34^{\mathrm{a}} \\
(-23.1)\end{array}$ & $\begin{array}{l}-0.27^{\mathrm{a}} \\
(-6.9)\end{array}$ & $\begin{array}{l}0.05^{\mathrm{a}} \\
(4.7)\end{array}$ & $\begin{array}{l}-0.31^{\mathrm{a}} \\
(-2.0)\end{array}$ & $\begin{array}{l}0.45^{\mathrm{b}} \\
(1.8)\end{array}$ & $\begin{array}{c}0.04^{\mathrm{a}} \\
(22.1)\end{array}$ \\
\hline $\mathrm{R}^{2}$ & 0.78 & 0.87 & 0.85 & 0.81 & 0.91 & 0.91 & 0.92 \\
\hline $\mathrm{N}$ & 32 & 26 & 71 & 53 & 40 & 50 & 51 \\
\hline
\end{tabular}

Notes: The values in brackets are the t-value ratio of the estimators. (a) and (b) designate respectively the significativity at 5\% and 10\%. Canada: 1969:12-2005:02, France: 1970:01-2004:10, Germany: 1969:12-2005:02, Italy: 1971:01-2005:02, Japan: 1969:12-2005:02, the UK: 1969:12-2005:01 and the USA: 1969:12-2005:02. 


\section{Appendix 2 - Stock prices and fundamental values ${ }^{21}$}

Germany

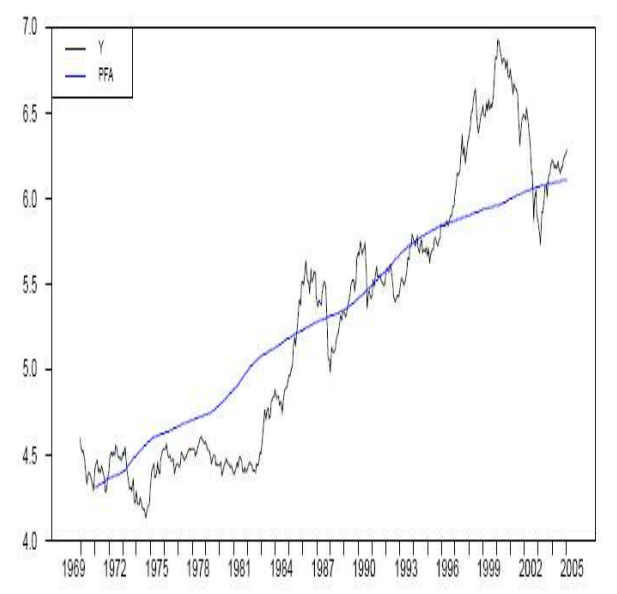

USA
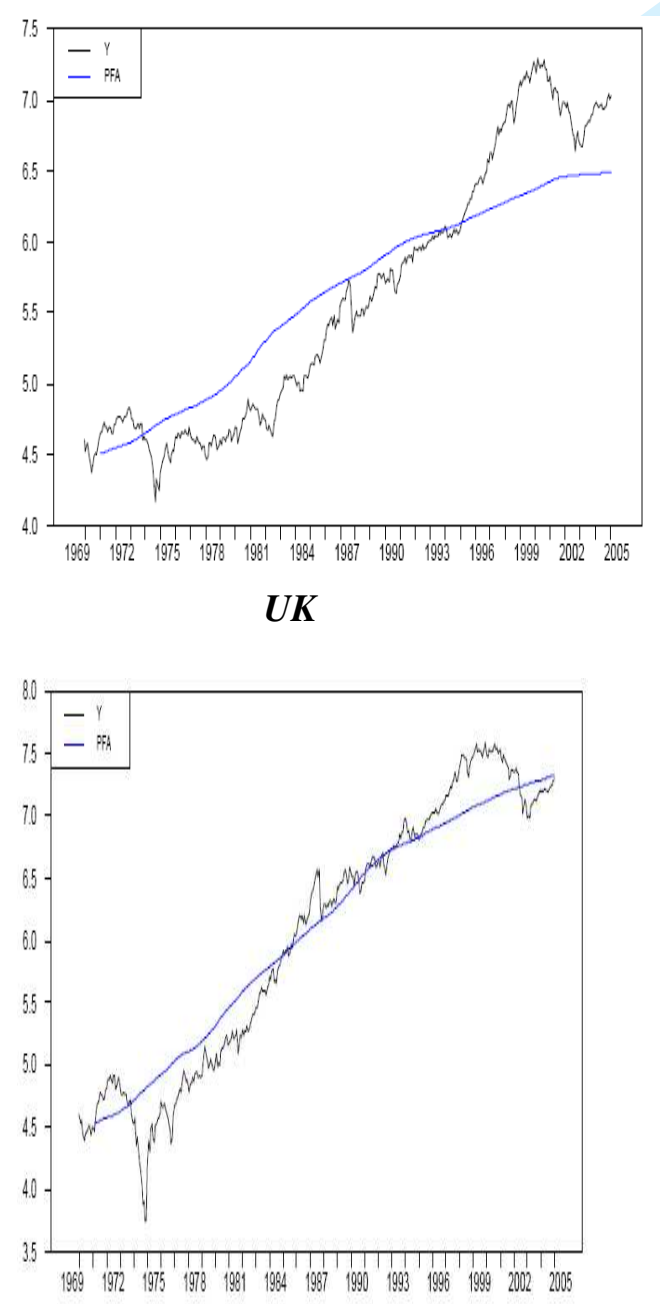

Canada

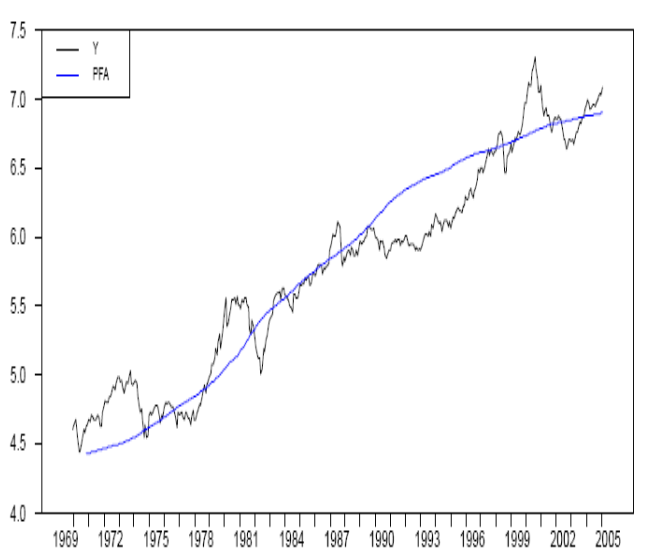

France

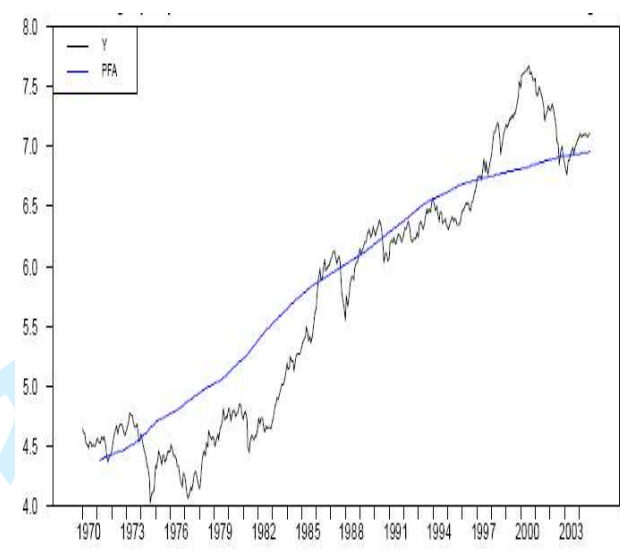

Italy

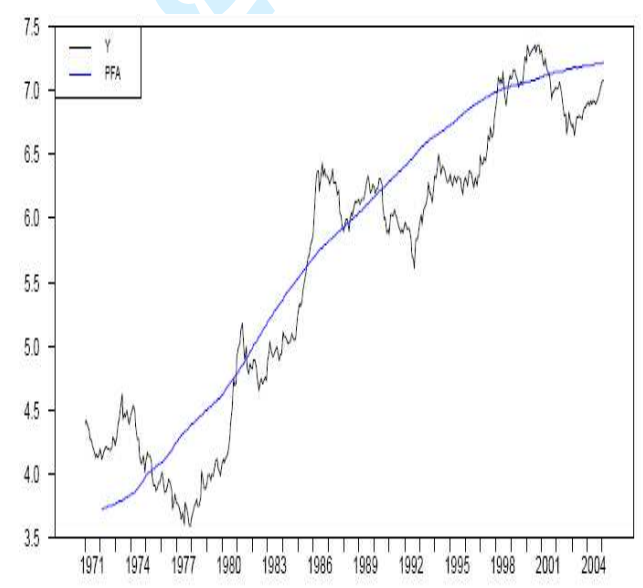




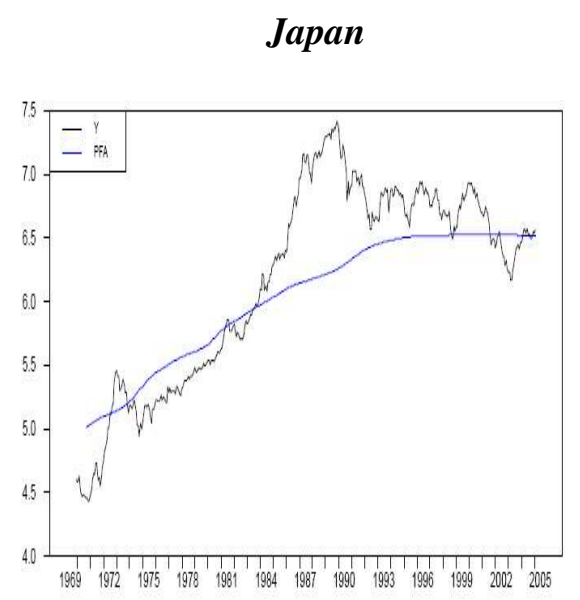

Note: Y and PFA are respectively the observed price and its estimated fundamental value in logarithm. 


\section{Appendix 3 - Stock price deviations: LECM estimations}

\begin{tabular}{|c|c|c|c|c|c|c|c|}
\hline & Germany & Canada & USA & France & UK & Italy & Japan \\
\hline $\mathrm{p}$ & 1 & 3 & 1 & 1 & 2 & 1 & 1 \\
\hline$\hat{\rho}$ & $\begin{array}{l}-0.015 \\
(-2.31)^{*}\end{array}$ & $\begin{array}{c}-0.011 \\
(-1.68)^{* *}\end{array}$ & $\begin{array}{c}0.06 \\
(0.9)^{*}\end{array}$ & $\begin{array}{l}-0.0001 \\
(-1.74)^{* *}\end{array}$ & $\begin{array}{c}-0.025 \\
(-2.95)^{*}\end{array}$ & $\begin{array}{l}-0.005 \\
(-0.63)\end{array}$ & $\begin{array}{c}-0.012 \\
(-2.05)^{*}\end{array}$ \\
\hline$\hat{\phi}_{1}$ & $\begin{array}{c}-0.013 \\
(-1.63)^{* *}\end{array}$ & $\begin{array}{l}0.017 \\
(0.4)\end{array}$ & $\begin{array}{l}-0.04 \\
(-1.8)^{* *}\end{array}$ & $\begin{array}{c}0.029 \\
(1.71)^{\text {*** }}\end{array}$ & $\begin{array}{l}-0.007 \\
(-1.15)\end{array}$ & $\begin{array}{c}-0.016 \\
(-1.81)^{* *}\end{array}$ & $\begin{array}{c}0.012 \\
(1.83)^{* *}\end{array}$ \\
\hline$\hat{\phi}_{2}$ & - & $\begin{array}{c}-0.019 \\
(-1.74)^{* *}\end{array}$ & - & - & $\begin{array}{c}-0.14 \\
(-2.92)\end{array}$ & - & - \\
\hline$\hat{\phi}_{3}$ & - & $\begin{array}{c}0.102 \\
(3.18)^{*}\end{array}$ & - & - & - & - & - \\
\hline$\hat{\alpha}_{0}$ & $\begin{array}{c}0.293 \\
(5.14)^{*}\end{array}$ & $\begin{array}{c}0.83 \\
(22.6)\end{array}$ & - & $\begin{array}{c}0.4 \\
(7.05)^{*}\end{array}$ & $\begin{array}{c}0.79 \\
(16.2)^{*}\end{array}$ & $\begin{array}{c}0.52 \\
(7.06)^{*}\end{array}$ & $\begin{array}{c}0.43 \\
(7.91)^{*}\end{array}$ \\
\hline$\hat{\alpha}_{1}$ & $\begin{array}{c}0.131 \\
(2.35)^{*}\end{array}$ & $\begin{array}{c}0.09 \\
(1.65)^{* *}\end{array}$ & - & - & $\begin{array}{c}0.09 \\
(1.65)^{\text {** }}\end{array}$ & $\begin{array}{l}0.16 \\
(2.0) \\
\end{array}$ & $\begin{array}{c}0.2 \\
(3.37)\end{array}$ \\
\hline$\hat{\alpha}_{2}$ & - & - & - & - & $\begin{array}{c}0.13 \\
(2.09)^{*}\end{array}$ & $\begin{array}{c}0.14 \\
(1.96)\end{array}$ & - \\
\hline$\hat{\alpha}_{3}$ & - & - & - & - & $\begin{array}{c}0.15 \\
(3.06)^{*}\end{array}$ & - & - \\
\hline$\hat{\alpha}_{0}^{\prime}$ & $\begin{array}{c}0.49 \\
(11.7)^{*}\end{array}$ & - & - & - & - & - & - \\
\hline$\hat{\alpha}_{0}^{\prime \prime}$ & - & - & - & $\begin{array}{c}0.51 \\
(11.67)^{*}\end{array}$ & - & - & - \\
\hline$\hat{\beta}_{0}$ & - & - & $\begin{array}{c}0.15 \\
(4.4)^{*}\end{array}$ & - & - & - & - \\
\hline$\hat{\theta}_{0}$ & $\begin{array}{l}-0.0007 \\
(1.65)^{* *}\end{array}$ & $\begin{array}{l}-0.011 \\
(-3.8)^{*}\end{array}$ & $\begin{array}{l}-0.008 \\
(2.57) \\
\end{array}$ & $\begin{array}{l}-0.011 \\
(-2.4)^{*}\end{array}$ & $\begin{array}{c}-0.022 \\
(-5.42)\end{array}$ & $\begin{array}{c}-0.011 \\
(-2.16)\end{array}$ & $\begin{array}{c}-0.001 \\
(-1.99)\end{array}$ \\
\hline$\hat{\theta}_{0}$ & - & - & - & - & - & - & $\begin{array}{c}0.29 \\
(1.64)^{* *}\end{array}$ \\
\hline$\hat{\theta}_{i}$ & - & $\begin{array}{c}0.22 \\
(1.7)^{* *}\end{array}$ & $\begin{array}{c}0.29 \\
(1.69)^{* * *}\end{array}$ & - & - & - & - \\
\hline$\hat{\theta}_{2}$ & - & - & - & - & $\begin{array}{c}0.25 \\
(1.76)^{* * *}\end{array}$ & - & - \\
\hline $\mathrm{R}^{2}$ & 0.49 & 0.60 & 0.44 & 0.53 & 0.46 & 0.17 & 0.21 \\
\hline$\sigma_{\mathrm{L}}$ & 0.04 & 0.03 & 0.03 & 0.04 & 0.04 & 0.06 & 0.04 \\
\hline $\mathrm{Q}(4)$ & 0.09 & 0.46 & 2.37 & 1.77 & 1.25 & 3.18 & 1.84 \\
\hline $\mathrm{Q}(12)$ & 3.56 & 31.01 & 10.06 & 13.1 & 14.9 & 17.56 & 5.8 \\
\hline J-B & $31.95^{*}$ & $23.58^{*}$ & $7.66^{* * *}$ & $27.54^{*}$ & $372.2^{*}$ & $20.3^{*}$ & $24.55^{*}$ \\
\hline
\end{tabular}

Note: Values under estimates are the Student t-values. $\mathrm{R}^{2}$ is the determination coefficient, J-B is statistic of Jarque-Berra test and $\sigma_{\mathrm{L}}$ is standard deviation of linear model. Q(4) and $\mathrm{Q}(12)$ are LjungBox statistics. $(*)$ and $(* *)$ designate respectively the significativity at $5 \%$ and $10 \%$. 
Appendix 4 - Estimating the transition functions $\Omega($.) ESTECM are estimated under $H_{0}^{a}, H_{0}^{b}$ and $H_{0}^{c}$

Germany
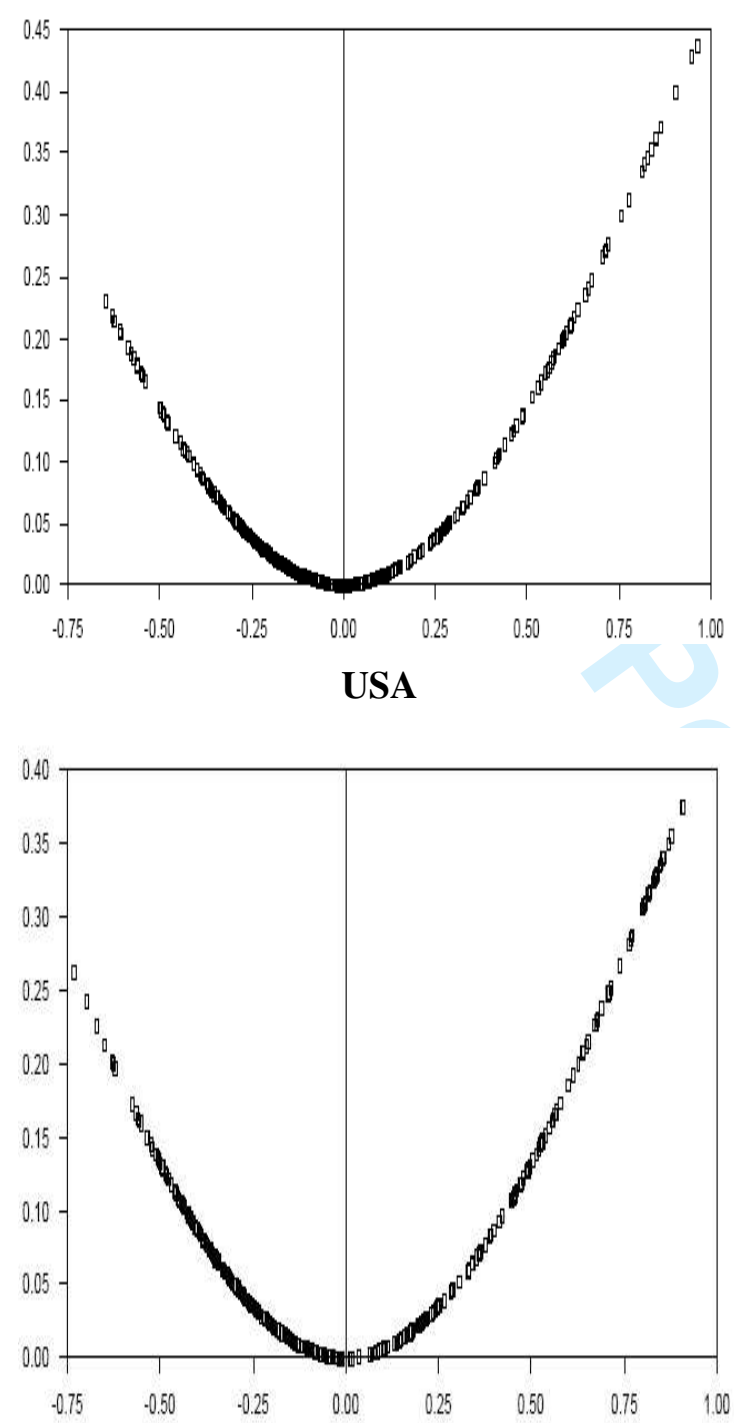

Canada
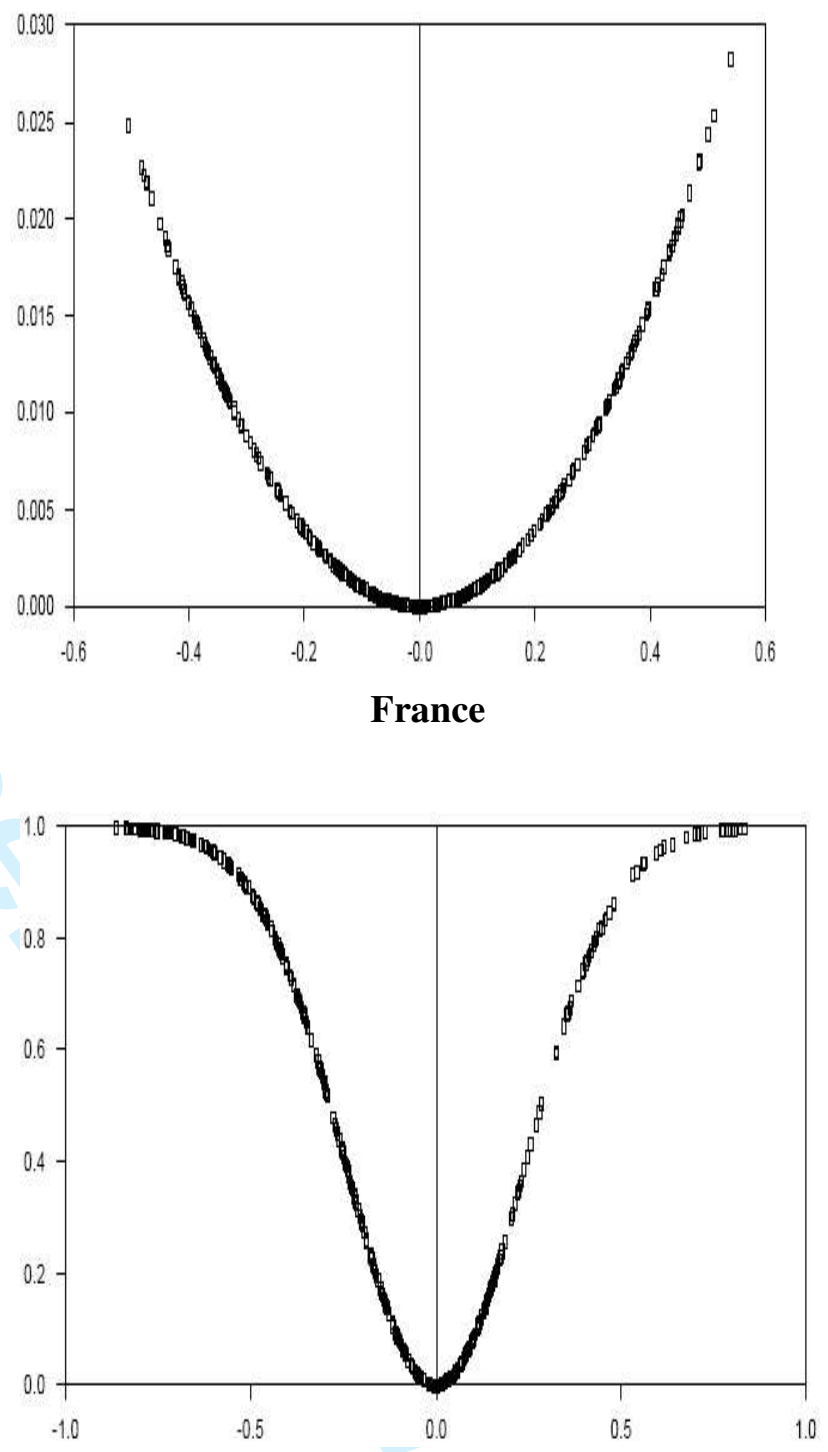
UK

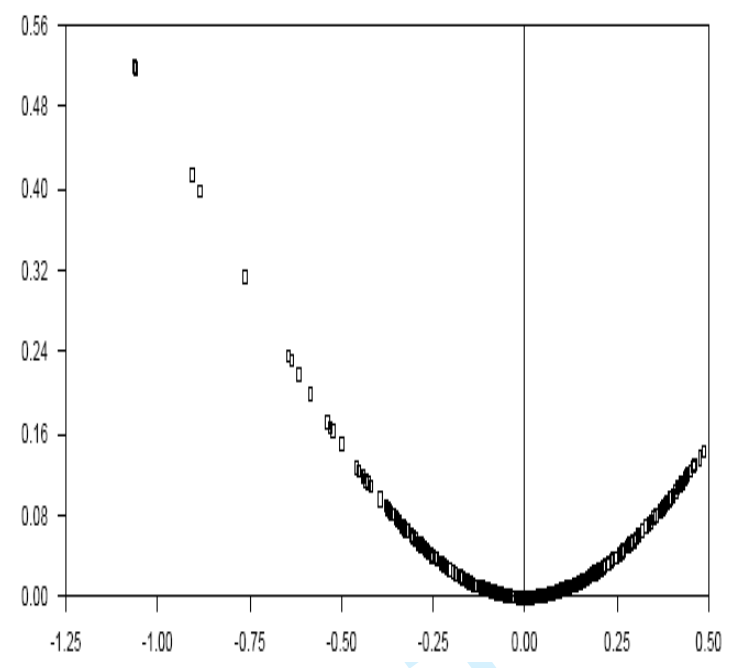

Italy

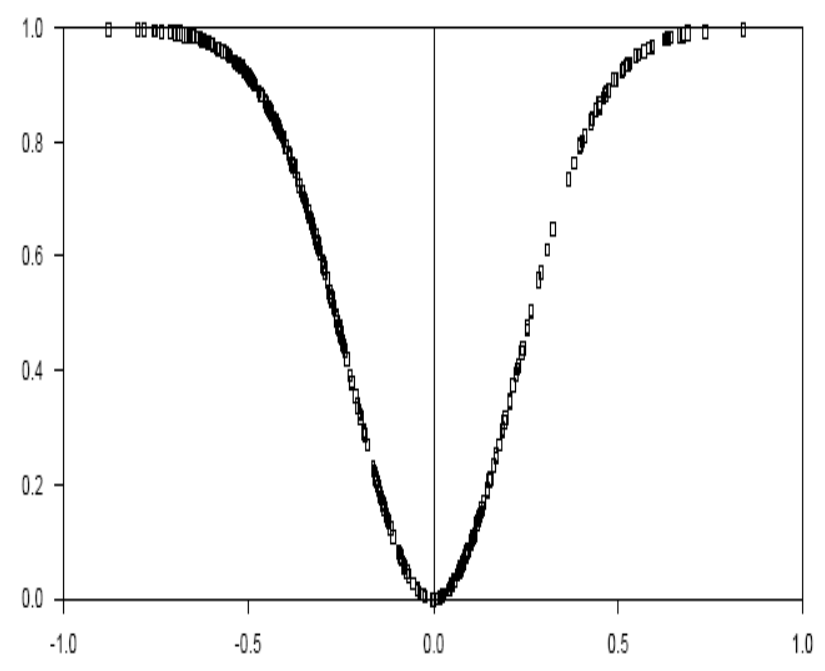

Japan

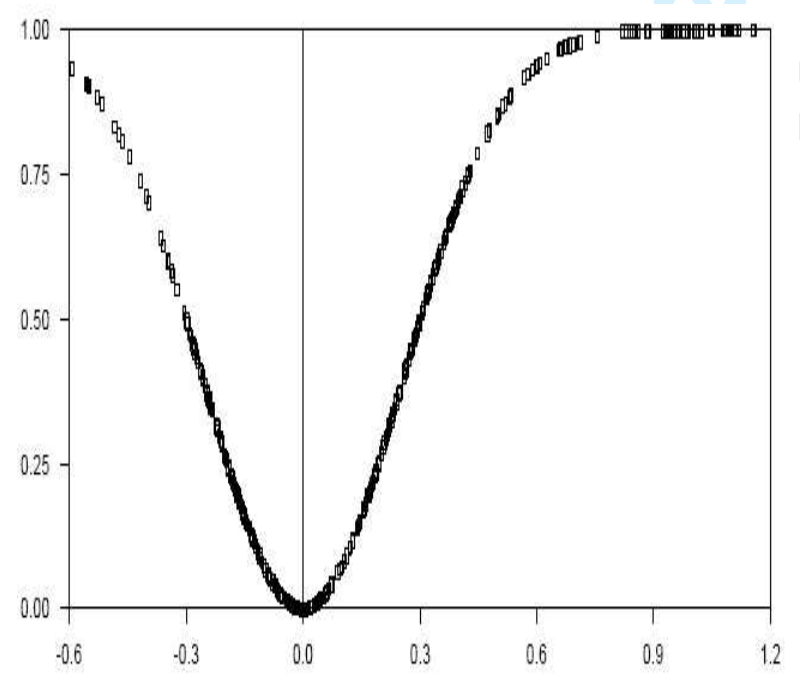

46

47

48

49

50

51

52

53

54

55

56

57

58

59 


\section{Appendix 5 - Misspecification tests}

ESTECM estimations under $H_{0}^{a}, H_{0}^{b}$ and $H_{0}^{c}$

\begin{tabular}{|c|c|c|c|c|c|c|c|}
\hline \multicolumn{8}{|c|}{ Tests of no error autocorrelation (p-values of $\mathrm{LM}_{\mathrm{SI}}$ ) } \\
\hline $\mathrm{q} /$ serie & Germany & Canada & USA & France & UK & Italy & Japan \\
\hline$q=1$ & 0.35 & 0.11 & 0.17 & 0.24 & 0.20 & 0.55 & 0.13 \\
\hline$q=2$ & 0.62 & 0.13 & 0.24 & 0.44 & 0.22 & 0.46 & 0.28 \\
\hline$q=3$ & 0.80 & 0.12 & 0.42 & 0.51 & 0.43 & 0.53 & 0.31 \\
\hline$q=4$ & 0.90 & 0.23 & 0.53 & 0.63 & 0.57 & 0.33 & 0.29 \\
\hline$q=8$ & 0.69 & 0.20 & 0.73 & 0.28 & 0.39 & 0.16 & 0.23 \\
\hline$q=12$ & 0.89 & 0.35 & 0.75 & 0.27 & 0.10 & 0.17 & 0.40 \\
\hline \multicolumn{8}{|c|}{ Test of parameter stability (p-values of $\mathrm{LM}_{\mathrm{c}, \mathrm{i}}, \forall \mathrm{i}=1,2,3$ ) } \\
\hline $\mathrm{LM}_{\mathrm{c}, 1}$ & 0.48 & 0.22 & 0.18 & 0.17 & 0.02 & 0.34 & 0.23 \\
\hline $\mathrm{LM}_{\mathrm{c}, 2}$ & 0.67 & 0.23 & 0.44 & 0.10 & 0.01 & 0.55 & 0.38 \\
\hline $\mathrm{LM}_{\mathrm{c}, 3}$ & 0.88 & 0.55 & 0.68 & 0.30 & 0.03 & 0.75 & 0.63 \\
\hline \multicolumn{8}{|c|}{ Test of no remaining nonlinearity (p-values of $\mathrm{LM}_{\mathrm{AMR}}$ ) } \\
\hline $\mathrm{d}^{\prime}=1$ & 0.84 & 0.63 & 0.97 & 0.19 & 0.11 & 0.11 & 0.11 \\
\hline $\mathrm{d}^{\prime}=2$ & 0.92 & 0.49 & 0.94 & 0.27 & 0.01 & 0.59 & 0.07 \\
\hline $\mathrm{d}^{\prime}=3$ & 0.94 & 0.57 & 0.87 & 0.46 & 0.13 & 0.11 & 0.06 \\
\hline $\mathrm{d}^{\prime}=4$ & 0.95 & 0.64 & 0.79 & 0.62 & 0.05 & 0.15 & 0.16 \\
\hline$d^{\prime}=5$ & 0.98 & 0.54 & 0.92 & 0.74 & 0.11 & 0.18 & 0.39 \\
\hline $\mathrm{d}^{\prime}=6$ & 0.98 & 0.47 & 0.92 & 0.63 & 0.14 & 0.13 & 0.07 \\
\hline $\mathrm{d}^{\prime}=7$ & 0.92 & 0.45 & 0.80 & 0.40 & 0.29 & 0.48 & 0.15 \\
\hline $\mathrm{d}^{\prime}=8$ & 0.92 & 0.29 & 0.93 & 0.37 & 0.04 & 0.16 & 0.23 \\
\hline $\mathrm{d}^{\prime}=9$ & 0.87 & 0.53 & 0.86 & 0.39 & 0.11 & 0.87 & 0.30 \\
\hline $\mathrm{d}^{\prime}=10$ & 0.68 & 0.43 & 0.80 & 0.52 & 0.03 & 0.30 & 0.13 \\
\hline $\mathrm{d}^{\prime}=11$ & 0.80 & 0.41 & 0.69 & 0.64 & 0.03 & 0.57 & 0.52 \\
\hline $\mathrm{d}^{\prime}=12$ & 0.66 & 0.32 & 0.66 & 0.68 & 0.07 & 0.74 & 0.29 \\
\hline
\end{tabular}




\section{Appendix 6 - Under- and overvaluation of stock price $\Pi\left(z_{t}\right)$ \\ ESTECM are estimated under $H_{0}^{a}, H_{0}^{b}$ and $H_{0}^{c}$}

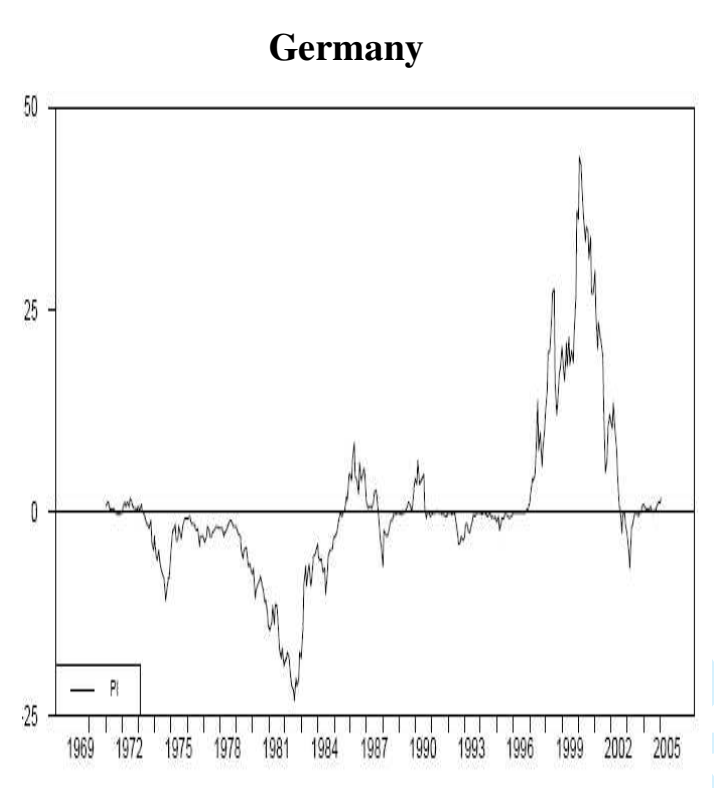

USA

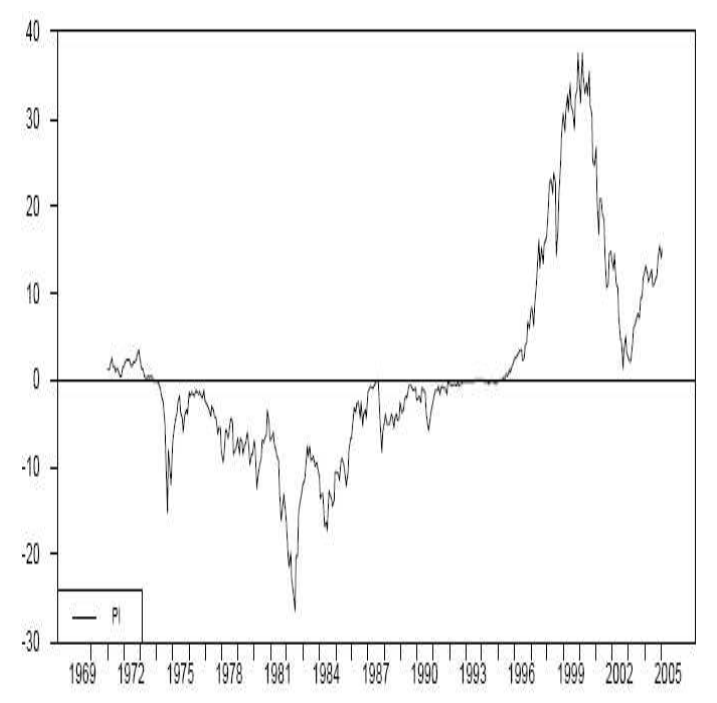

Canada

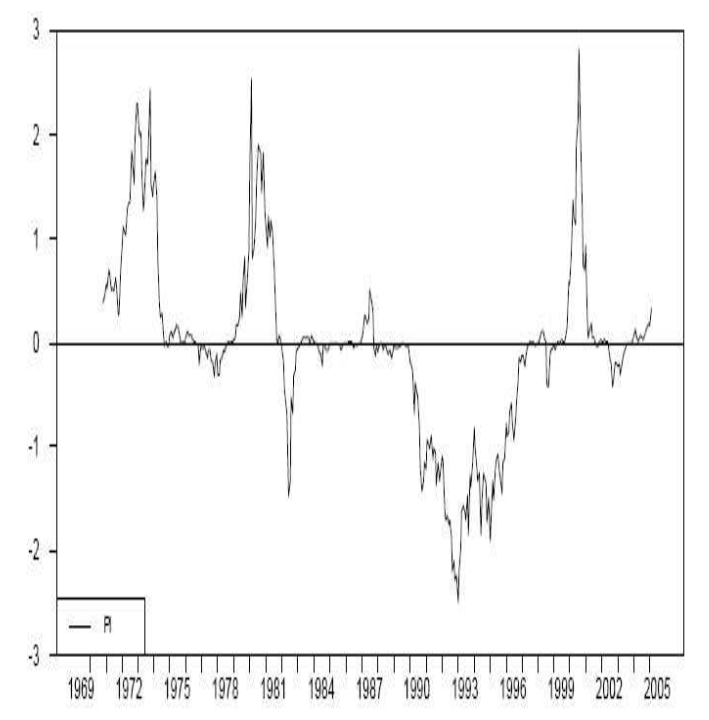

France

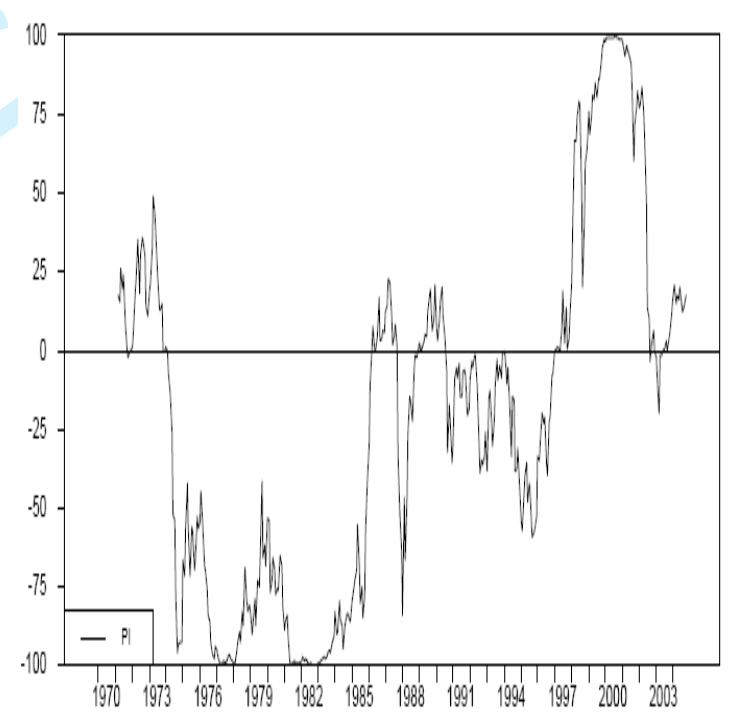


UK

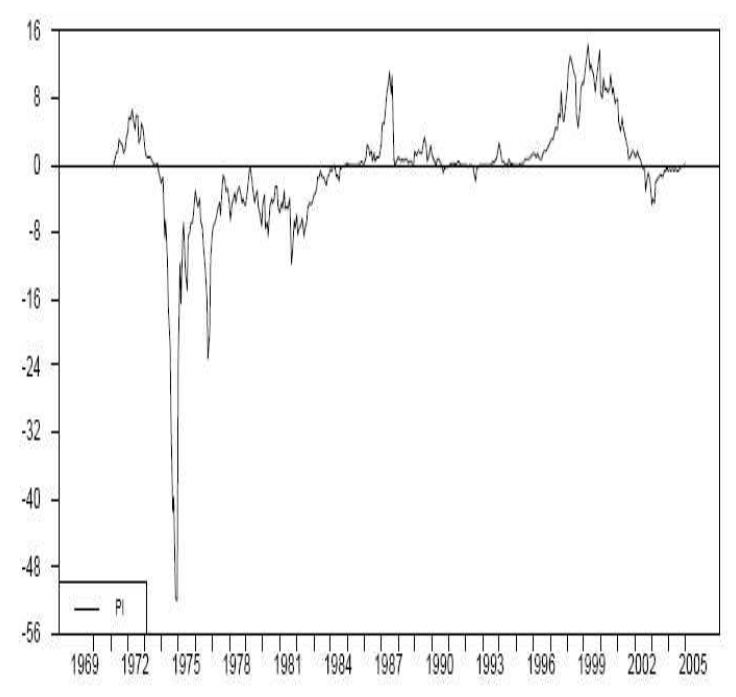

Japan

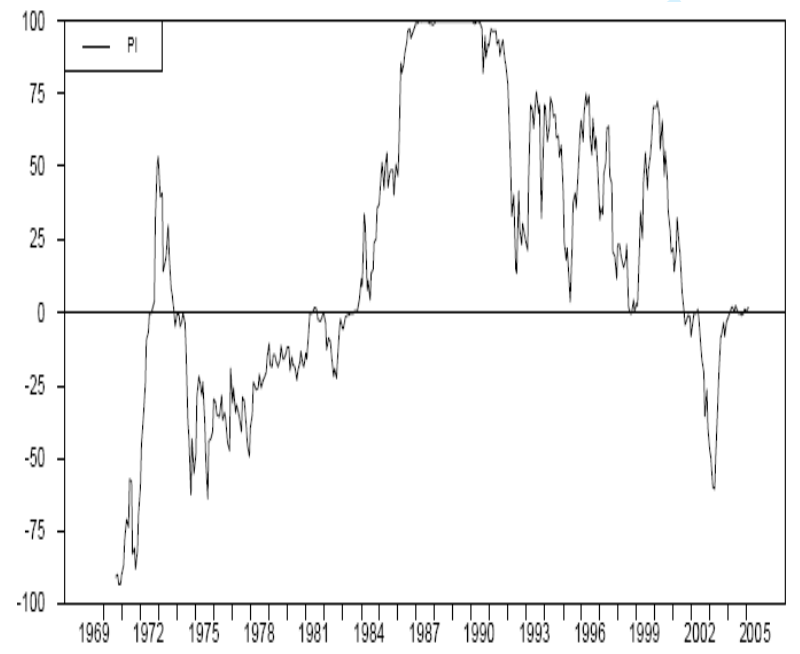

Italy

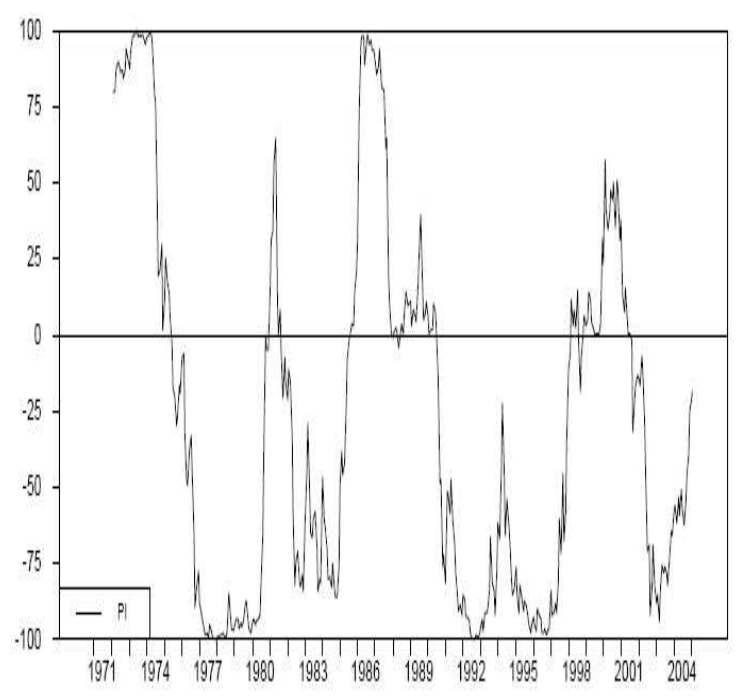




\section{Appendix 7 - Stock price adjustment speeds $\Psi(z t)$}

ESTECM are estimated under $H_{0}^{a}, H_{0}^{b}$ and $H_{0}^{c}$

Germany

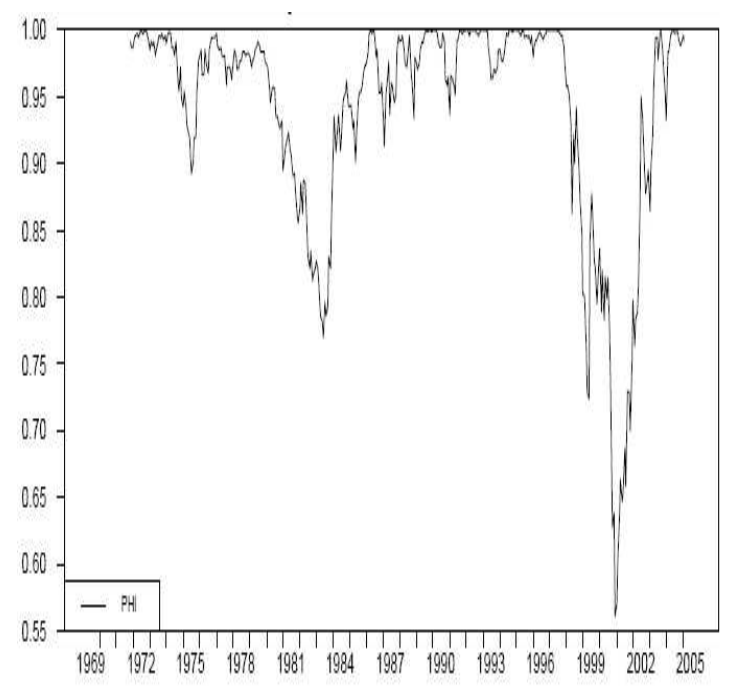

USA

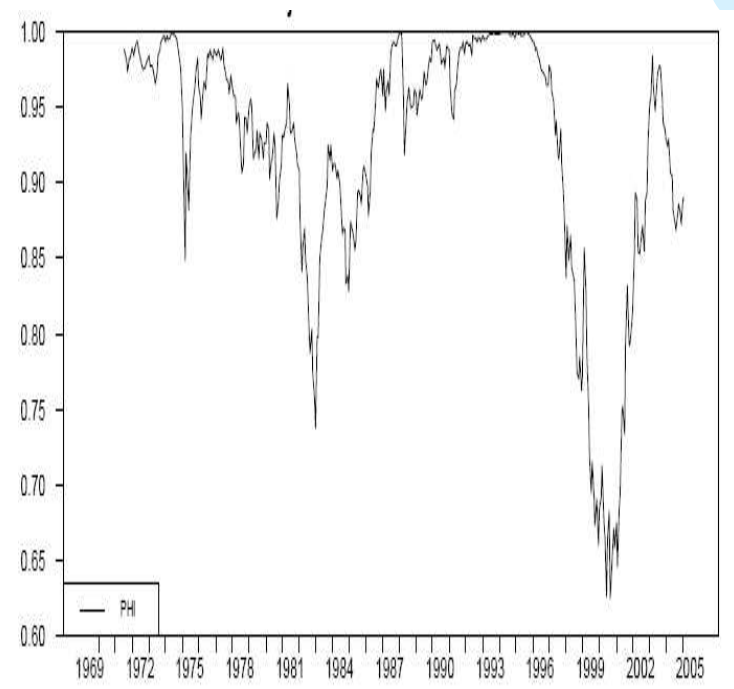

Canada

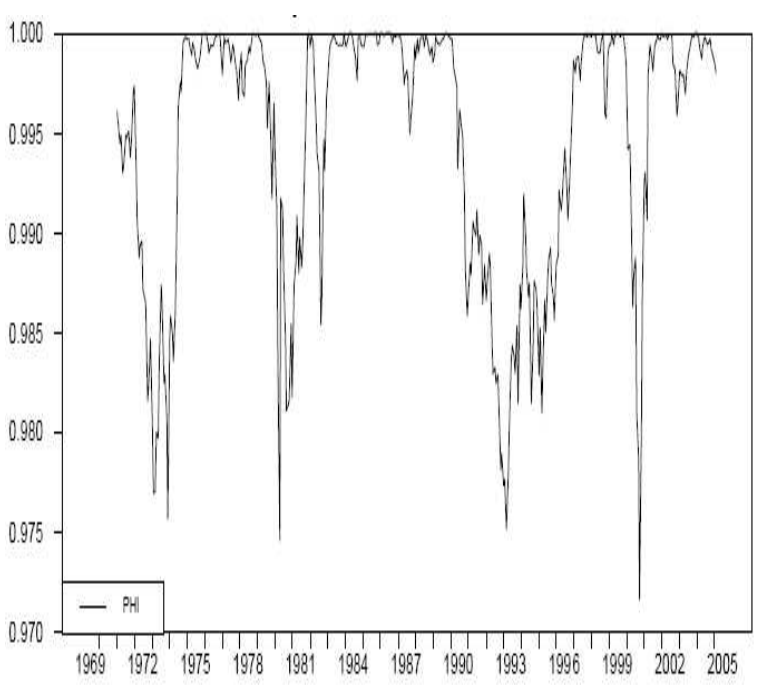

France

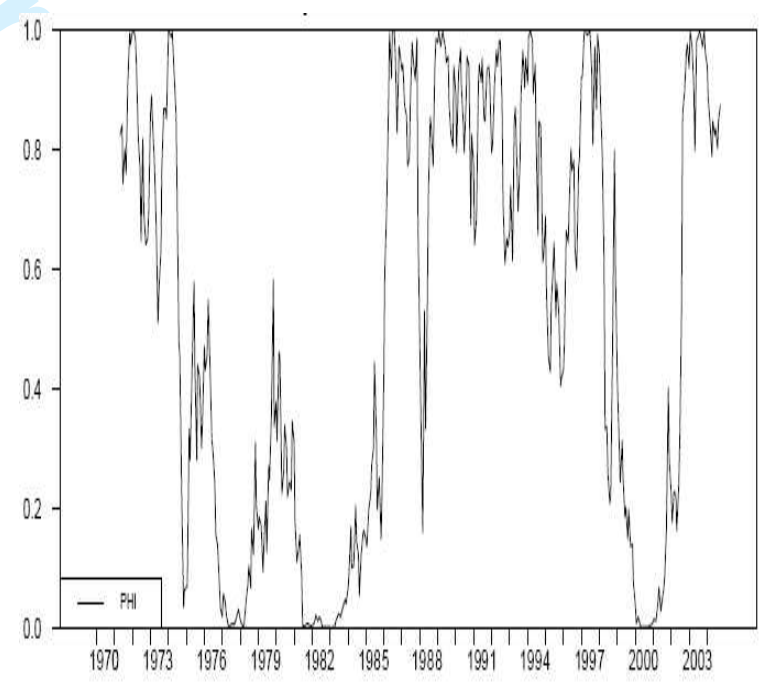


UK

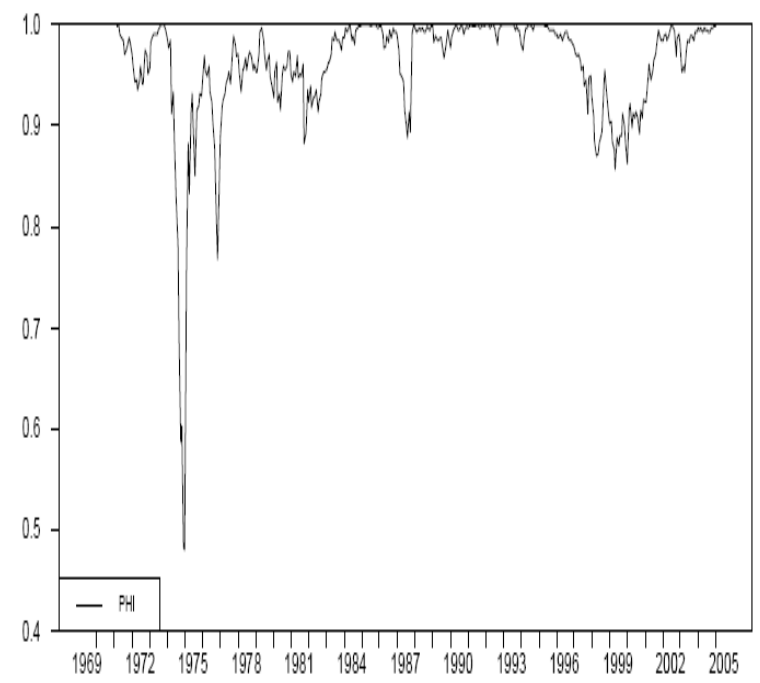

Japan

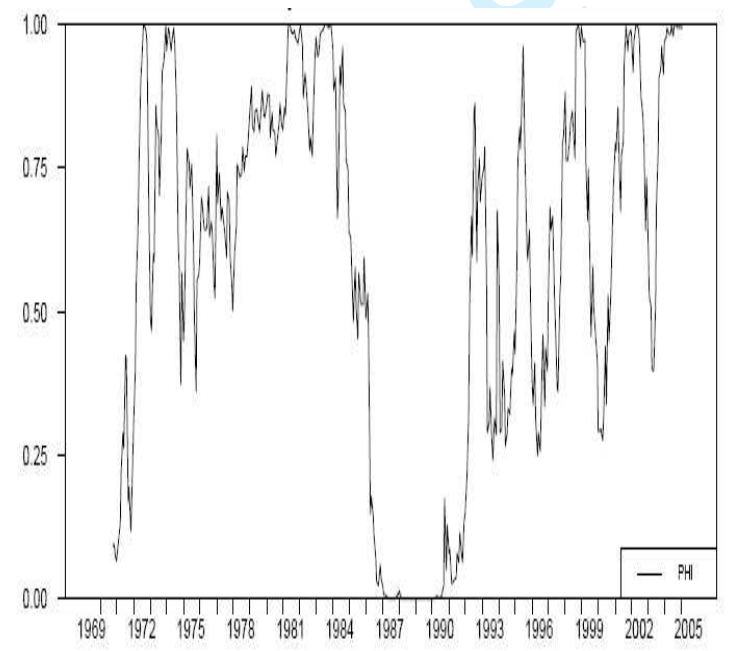

Italy

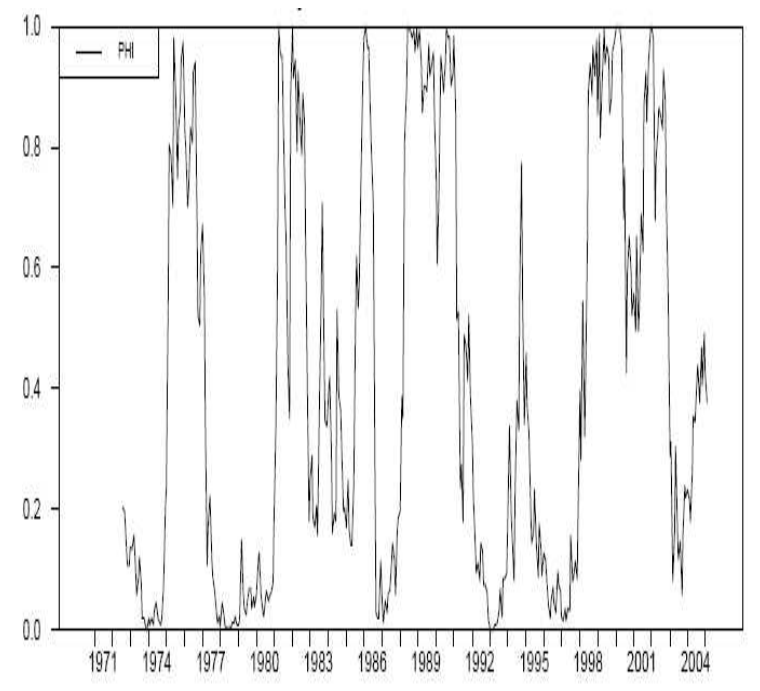

